IZA DP No. 8207

Life Events and Subjective Well-being:

The Case of Having Children

Peder J. Pedersen

Torben D. Schmidt

May 2014 


\title{
Life Events and Subjective Well-being: The Case of Having Children
}

\author{
Peder J. Pedersen \\ Aarhus University, \\ SFI-The Danish National Centre for Social Research and IZA \\ Torben D. Schmidt \\ University of Southern Denmark
}
Discussion Paper No. 8207
May 2014

IZA
P.O. Box 7240
53072 Bonn
Germany

Phone: +49-228-3894-0

Fax: +49-228-3894-180

E-mail: iza@iza.org

Any opinions expressed here are those of the author(s) and not those of IZA. Research published in this series may include views on policy, but the institute itself takes no institutional policy positions. The IZA research network is committed to the IZA Guiding Principles of Research Integrity.

The Institute for the Study of Labor (IZA) in Bonn is a local and virtual international research center and a place of communication between science, politics and business. IZA is an independent nonprofit organization supported by Deutsche Post Foundation. The center is associated with the University of Bonn and offers a stimulating research environment through its international network, workshops and conferences, data service, project support, research visits and doctoral program. IZA engages in (i) original and internationally competitive research in all fields of labor economics, (ii) development of policy concepts, and (iii) dissemination of research results and concepts to the interested public.

IZA Discussion Papers often represent preliminary work and are circulated to encourage discussion. Citation of such a paper should account for its provisional character. A revised version may be available directly from the author. 


\section{ABSTRACT \\ Life Events and Subjective Well-being: The Case of Having Children}

The literature on Happiness and Subjective Well-Being (SWB) has been dominated by studies of the impact from income and labour market status - and the impact on happiness from changes in these determinants. It seems obvious to expect an impact from noneconomic factors as well. In the present paper we focus on the eventual impact on SWB from having children. The dominant result in the rather few studies until now is the finding of no or even a negative - impact on subjective well being following birth of a child. We focus on the impact from having children using two very big panel data sets. The first is the European Community Household Panel (ECHP) with data collected over 8 annual waves from 1994 to 2001 in 15 EU member countries. Observations are available for up to 15 countries with big differences in fertility levels, child care institutions and labour force participation for married women. At the same time, the ECHP data contains a lot of relevant demographic and labour market background variables to be included in the econometric analyses of the SWB impact from children. The second data set is The German Socio Economic Panel (GSOEP). Like the ECHP, the GSOEP data contains many relevant background factors. This presents a unique opportunity to combine the cross country perspective in the ECHP data with the possibility presented by the GSOEP of following the impact from giving birth over a significantly longer period including approximately 11.000 households.

JEL Classification: D1, I31, J13

Keywords: $\quad$ subjective well-being, life events, panel data

Corresponding author:

Peder J. Pedersen

Department of Economics and Business

Fuglesangs Allé 4

building 2632, room 137

8210 Aarhus V

Denmark

E-mail: ppedersen@econ.au.dk 


\section{Introduction}

The demographic challenge facing most OECD countries consists of two elements, a decline in mortality and a strong decline in fertility, implying together the ageing of many high income countries, mostly in Europe, but also e.g. in Japan. The topic here is to focus on one special aspect of these big demographic changes, which is the trend in fertility. More precisely, the purpose in the present paper is to examine the impact on subjective well-being from having children in a setting of low or very low fertility in many countries. We apply data from the German Socioeconomic Panel (GSOEP) and the European Community Household Panel (ECHP) to describe and analyse the impact from having children on subjective well-being. We include anticipation and adaptation to the life event of having your first child.

Section 2 contains a brief survey of the fairly few contributions to analyses of the impact from children on subjective well-being. Section 3 contains a brief survey of the trend in European fertility which has resulted in the present "scarcity" of children in many countries. In a cross-country perspective trends differ following a North-South divide, however with Germany as a notable exception. At the same time we relate the trends in fertility to the trends in female labor force participation. In a cross-European context the relationship between fertility and participation has shifted from being predominantly negative to being predominantly positive. This last observation relates to the brief survey in Section 4 of cross-country differences in family oriented policies consisting of costs and availability of child care institutions along with changes in family related cash benefits. There is an obvious simultaneity in this area where policy can have an impact on fertility at the same time as changes in fertility and trends in labor force participation may influence the effects from having children on subjective well-being.

Next, Section 5 summarizes descriptive evidence regarding the impact on subjective well-being from having children and becoming parents based on data from the ECHP covering $11 \mathrm{EU}$ countries over the 8 years 1994 - 2001 and based furthermore on data from the GSOEP covering a longer panel. Section 6 presents estimation results from an analysis of how having children or experiencing the birth of a child influences parental subjective well-being. Finally, Section 7 summarizes and discusses results. 


\section{Earlier studies}

A main impression from the empirical literature on the interaction between SWB and children is that the evidence seems to be very mixed. There does not seem to be consensus on the sign of the impact of children on SWB. Further, there is clear evidence of differences in the results depending on whether the issue is the impact from the birth of a child, especially birth of a first child, or the eventual impact from the number of children in the family. The results also seem to vary depending on the national and personal background, i.e. the type of welfare state in which a specific family lives, and on marital status of the mother. A final aspect in the literature where panel data are necessary is whether anticipation and adaptation effects are present in the sense of an eventual impact before, for instance the birth of a first child and further the question of how SWB changes over time after a life event, here the birth of a child.

A natural starting point in this area with an economic approach is the seminal book on the economics of the family by Becker (1981). In the present context, the expectation based on Becker (1981) is a positive impact from children as individuals are assumed to enter into a family and to have children as utility increasing activities. The empirical results, of which a brief and partial survey is presented below, are however as mentioned not in perfect harmony with this expectation, but more mixed. This might reflect that the decision, especially regarding having the first child, is taken behind a veil of ignorance.

In a compact survey of results Hillerås et al. (2001) in their section on the impact on SWB from marital status and children do not report any specific results regarding the impact from a birth or from the number of children in a family. Instead, they report as a general result that married individuals were happier after their children had left home, i.e. a reverse of the standard "empty nest” hypothesis. Further, they report that contact with children improves life satisfaction among elderly. Part of the seeming paradox between utility theory and the results in a significant number of empirical studies could thus be that the impact from having children should be considered in a lifelong perspective. On the other hand, Suh et al. (1996) claim that only recent life events matter. This could however be relevant when looking into the impact from a change, i.e. a birth - especially a first birth - relative to the impact from the state of having children in the family.

Clark and Oswald (2002) present a number of results using cross-section regressions to find monetary valuations of the importance of life events. Veenhoven (2002) comments on this approach and points to the relevance of using panel data to evaluate the impact from life events. One of these is having a child where Clark et al. (2008) based on GSOEP data find a negative impact on SWB 
for both women and men but full adaptation, i.e. return to the pre-birth SWB level after 5 years. Anticipation effects before birth are however found to be positive. Clark and Georgellis (2013) analyze the adaptation to several life events using 18 waves of the BHPS. They find complete and fast adaptation to marriage, divorce, birth of a child and widowhood but for men, unemployment still has a negative impact on SWB after 5 years. In relation to the main focus in the present paper, the SWB profile around a birth shows a decline at the time of the birth followed by a return to the pre-birth level.

Assvee et al. (2005) use ECHP data to analyze the impact on a number of well-being measures from child bearing. The well-being measures are household income, poverty status and a number of deprivation indices. They find a quite strong impact on a total deprivation index from single parenthood in the liberal type of welfare states. The Mediterranean type of welfare states have the highest overall average level for the total deprivation index, however the variation between family types is fairly small.

Hansen et al. (2009) analyze a Norwegian survey consisting of childless, parents with resident children and “empty nest” parents. They find only a - positive - impact for women compared with the childless. In Hansen (2012), a common belief about parenthood as central for a meaningful life is shown to be in contrast to the results in many empirical studies finding lower well-being from having children. Kohler et al. (2005) are using data from a long run Danish register of MZ twins. They analyze the impact from the number of children, finding it to be insignificant for women and surprisingly - positive and significant, however numerically small, for men. At the same time they analyze the impact from having a first birth. This is found to have a big positive impact for women while subsequent births are found to have a negative or no effect. This kind of asymmetry might be part of the explanation of finding no impact in a number of cases from the number of children.

Angeles (2010a) concludes that empirical results have so far been dominated by negative effects from having children. Using BHPS data he finds, however, a positive impact when only married women are included in the analysis. The impact is further found to be increasing in the number of children. Below we use the same strategy and focus on married and cohabiting women and singles separately. Plagnol and Scott (2011) also use the BHPS data. Their focus is however slightly different as they look into the impact from life events on perceptions on what matters for quality of life. Regarding the impact from birth of the first child they find a significant positive impact on perception of family as important and at the same time - not surprisingly - a negative impact on the perception of the family financial situation as important. Myrskylä and Margolis (2012) are using 
BHPS and GSOEP data and find happiness to be increasing around the birth of the first child, subsequently returning to the pre-birth level. Having up to two children is found to increase happiness in both countries.

Powdthavee (2010) has no new empirical results but concludes in a general discussion that the finding of almost zero association between having children and happiness reflects the need for more comprehensive research also including more results from outside the OECD area. This approach is taken in Margolis and Myrskylä (2011) working with data for 86 countries coming from the World Value Survey. The problem reaching conclusive evidence is illustrated by their presentation of results from two model specifications. The dependent variable is happiness level in both models. The covariates in the first model are number of children, gender and age. The finding here is a significant positive impact from having $1-3$ children, while no impact is found in case of 4 or more children. But including income, socio-economic and marital status in the second of the models results in the finding of significantly negative impact from children.

In a broad survey of international results, Blanchflower (2009) concludes that the dominant result is children having a negative impact on parental SWB. This is to some extent supported in Angeles (2010b) following up on the work in Clark et al. (2008). Angeles uses BHPS data and finds the impact from the number of children to be significantly negative for women. The birth of a child has a significantly positive impact for women, but only in the year of the birth and - anticipating - in the year preceding the birth. Having given birth to a child has however an insignificant impact on SWB in up to 5 and more years after the birth.

Finally, Cáceres-Depiano and Simonsen (2010) study the impact of increases in family size, not on SWB directly but on the risk of divorce, participation in welfare programs and risk of poverty and the impact on certain health risks for the mother. Using US data they find that increases in family size results in higher risks in the mentioned areas.

\section{Socioeconomic background}

An obvious motivation for focussing on children and well-being is the extremely dramatic decline in fertility occurring in Europe over the last 50 years. Figure 1 shows fertility rates in 6 Northern European countries from 1960 to $2010^{1}$. UK is the first country to cross the replacement level at a fertility rate slightly above 2 in the late 1960s followed a few years later by Denmark, France, the

\footnotetext{
${ }^{1}$ Goldstein et al. (2013) report quite strong further declines in fertility in a number of European countries following big increases in unemployment rates.
} 
Netherlands and Germany. The decline in fertility in the former GDR is extremely dramatic in the first decade after re-unification. From around 2000 fertility is at the same low level in the states making up the former East and West Germany. In Ireland the fertility rate is way above the other countries until around 1980. But in the late 1980s Ireland similar to the other countries in Northern Europe, excluding Germany, crosses the replacement level of the fertility rate.

Figure 2 shows the even more dramatic change occurring in the four Southern European countries Greece, Spain, Italy and Portugal. In those countries fertility crosses the replacement level in the second half of the 1970s and ends at a significantly lower level than in Northern Europe. In both country groups we observe signs of a moderate trend shift towards an increase in fertility rates over the last decade. In relation to the present topic, Figures 1 and 2 do not carry any predictions regarding the relationship between children and subjective well-being. Fertility could go down due to less well-being attached to children - or child related happiness could increase as children become less numerous. 
Figure 1. Fertility, Northern Europe, 1960-2010.

(Sources: Eurostat. Germany, from 2000 Eurostat. Former East and West Germany, Human Fertility Database. East and West Berlin excluded.

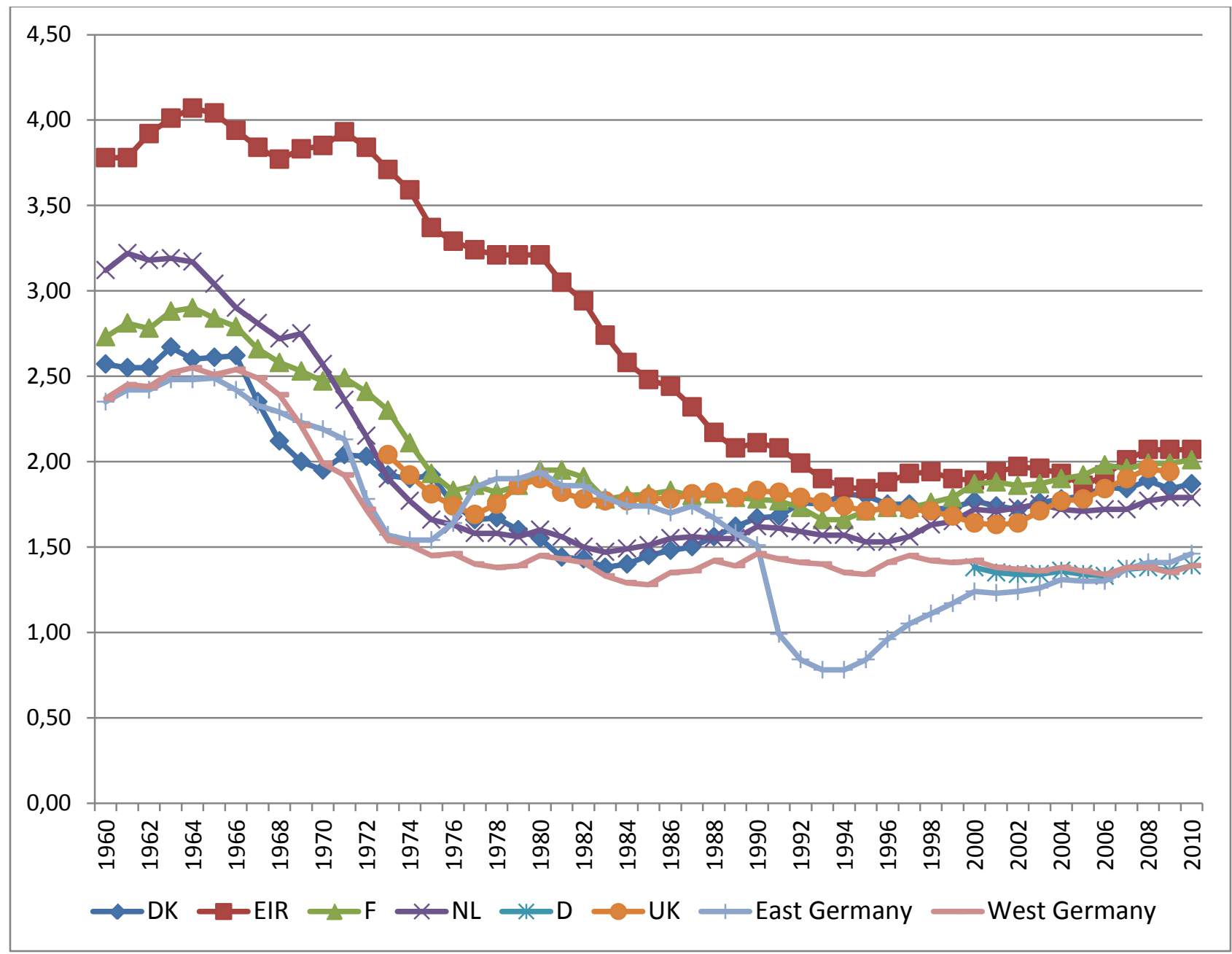


Figure 2. Fertility, Southern Europe, 1960-2010. (Eurostat).

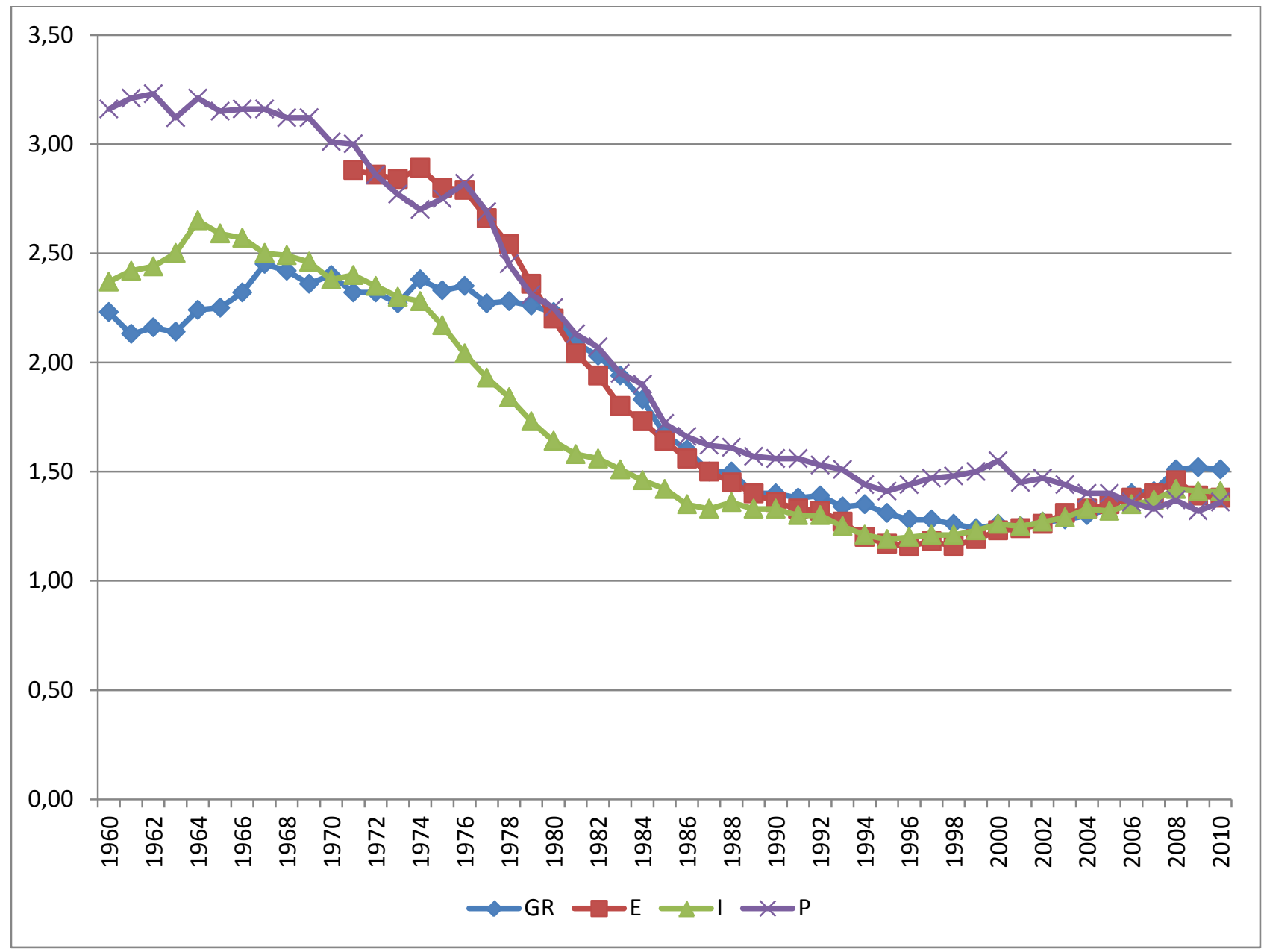

Another "grand" hypothesis could be that Figures 1 and 2 simply reflect women entering the labor market, to an increasing degree in full time jobs and that fewer children is an effect of this structural shift. This, however, is a clear simplification of a more complex story as shown in Figure 3. For the years 1960 - 2000 Figure 3 shows the annual correlation between fertility rate and the female labor force participation rate in 22 OECD countries. The main point in this correlation profile is obviously the shift of sign from negative to positive at about the same time when fertility crosses the replacement level. Figure 3 is a reflection of both structural changes and policy changes in the area of family policy and contributes presumably to explain the Southern European countries ending up at a significant lower fertility level than the countries in Northern Europe. 
Figure 3. Correlation between the total fertility rate and female labor force participation rate, 19602000. (source: Engelhardt and Prskawetz (2005)).

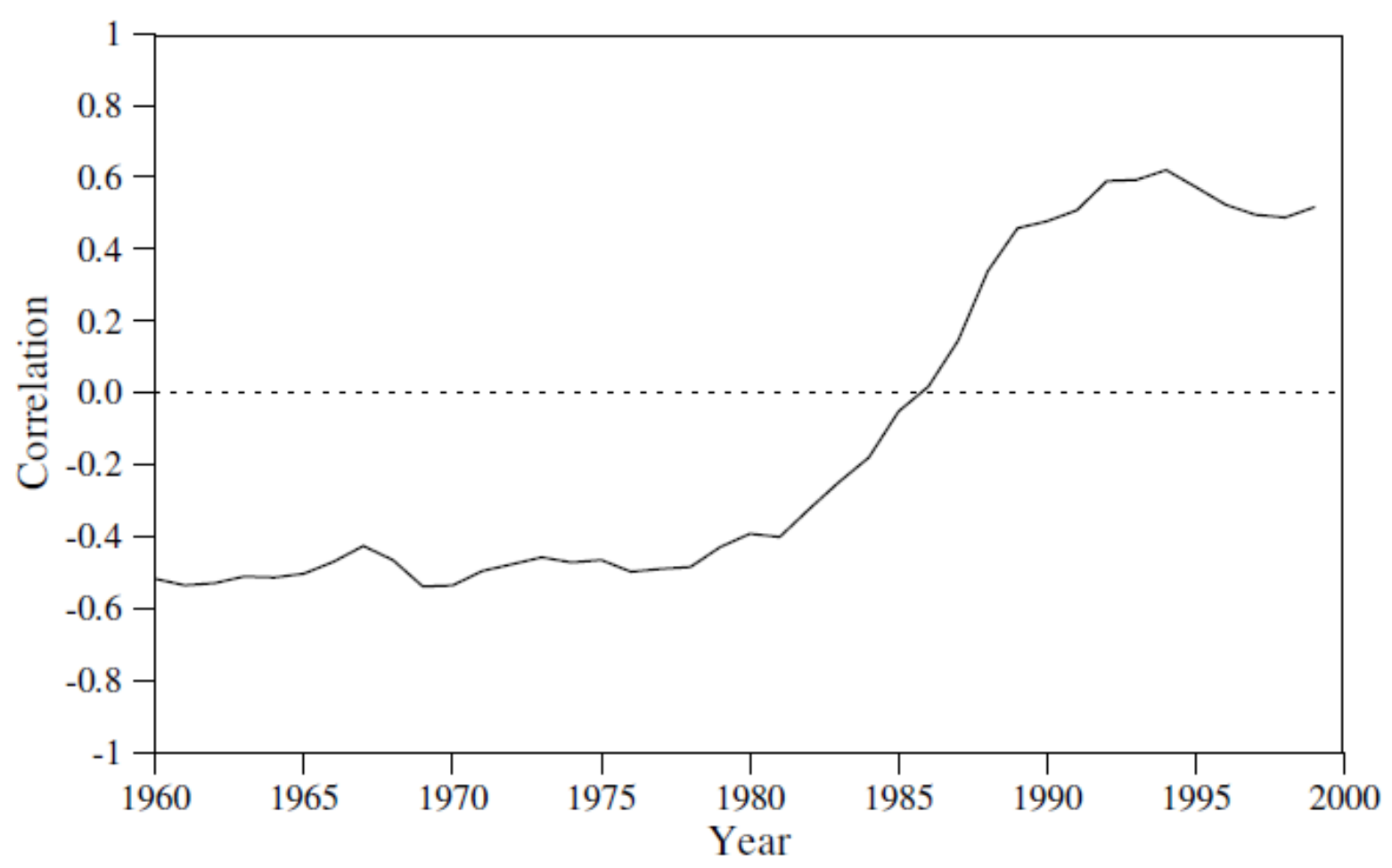

\section{Some trends in family policy}

The original welfare state typology introduced by Esping-Andersen (1990) classified countries into liberal, conservative and social-democratic welfare states, later expanded by including a Southern European model as a fourth category (e.g. Ferrera, 1996). With explicit focus on family policy Korpi (2000) suggested a distinction between three types of regimes based on a number of relevant family policy indicators, i.e. dual-earner regimes, general family support regimes and marketoriented regimes.

Based on this approach, Engster and Stensöta (2011) sets up a calculation of an average family policy support index, expanding Korpi (2000) by changing the group of market-oriented regimes to be renamed "low family support regimes", as this group includes liberal countries with a clear market orientation along with Southern European states depending mostly on childcare based on extended family and kin networks. The average family support index from Engster and Stensöta (2011) for the countries included in the present analysis is shown in Figure 4.

Engster and Stensöta (2011) include 20 countries in their analysis and the average family support index for all the countries comes out in good accordance with the original Esping-Andersen (1990) 
typology, i.e. 4 nordic social-democratic type countries on top, followed by 5 continental type welfare states and with the lowest values to liberal type and Southern European type welfare states.

Figure 4. Family policy support index. Average of 1995, 2000 and 2005. (Source: Engster and Stensöta (2011).

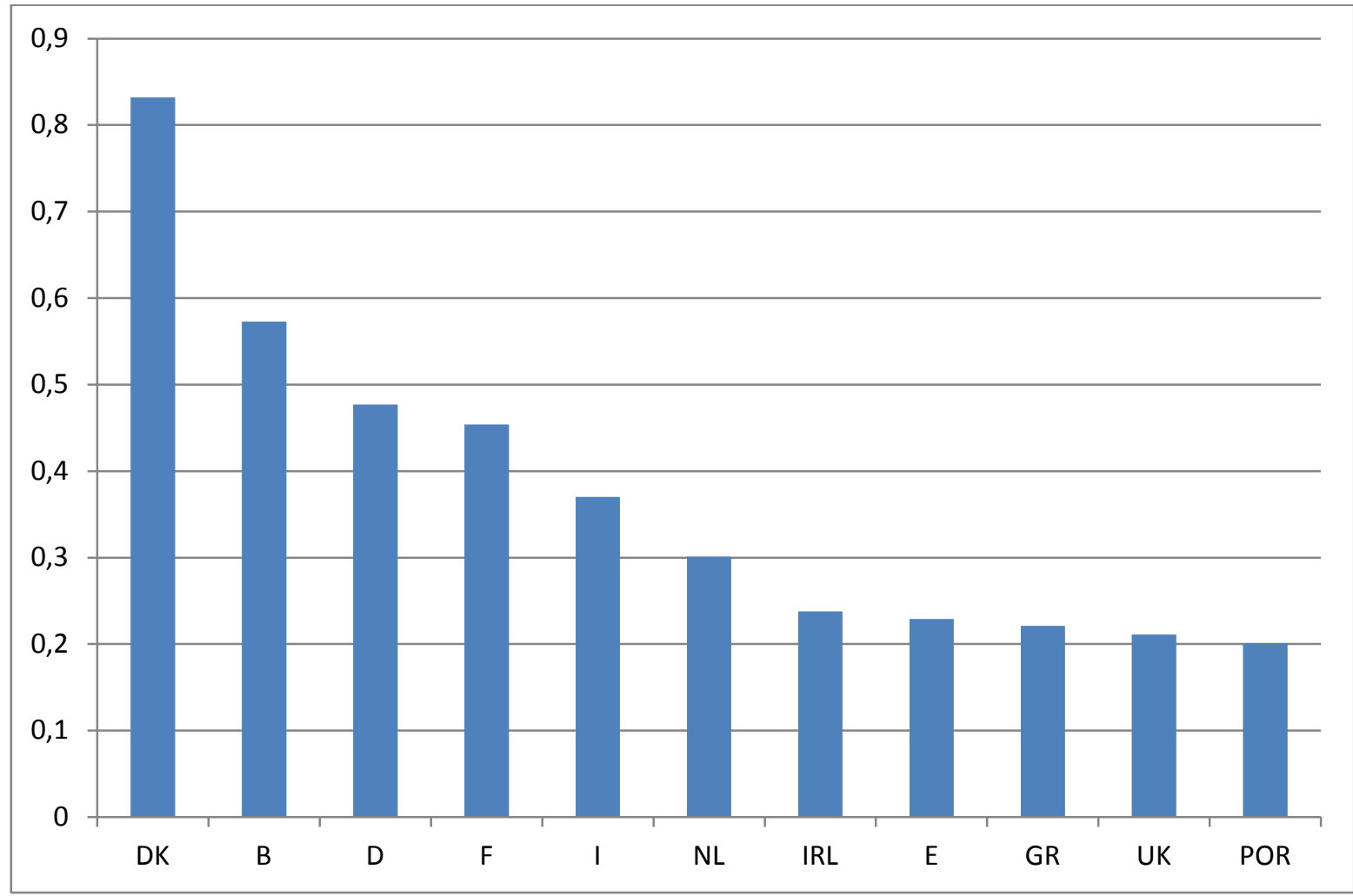

The purpose of introducing such measures of family policy in the present paper is two-fold. First, as a simple test for the eventual correlation between fertility and family policy indicators, and secondly to evaluate whether the impact on mothers well-being from having children relates to the scope and ambitions of family policy in the country of residence. Comparing the ranking of countries relative to the family support index in Figure 4 with the ranking according to fertility in the same group of countries it is obvious that there is no simple short run dependence between fertility and family policy as measured here. Actually, the two "neighbouring” countries in the middle of the distribution in Figure 4, France and Italy, have respectively the highest and the lowest fertility in 2005, cf. Figure 5. For the group of countries included in the present analysis the simple correlation between the level of fertility and the family support index is 0.32 . 
Figure 5. Fertility rates 2005. (Eurostat)

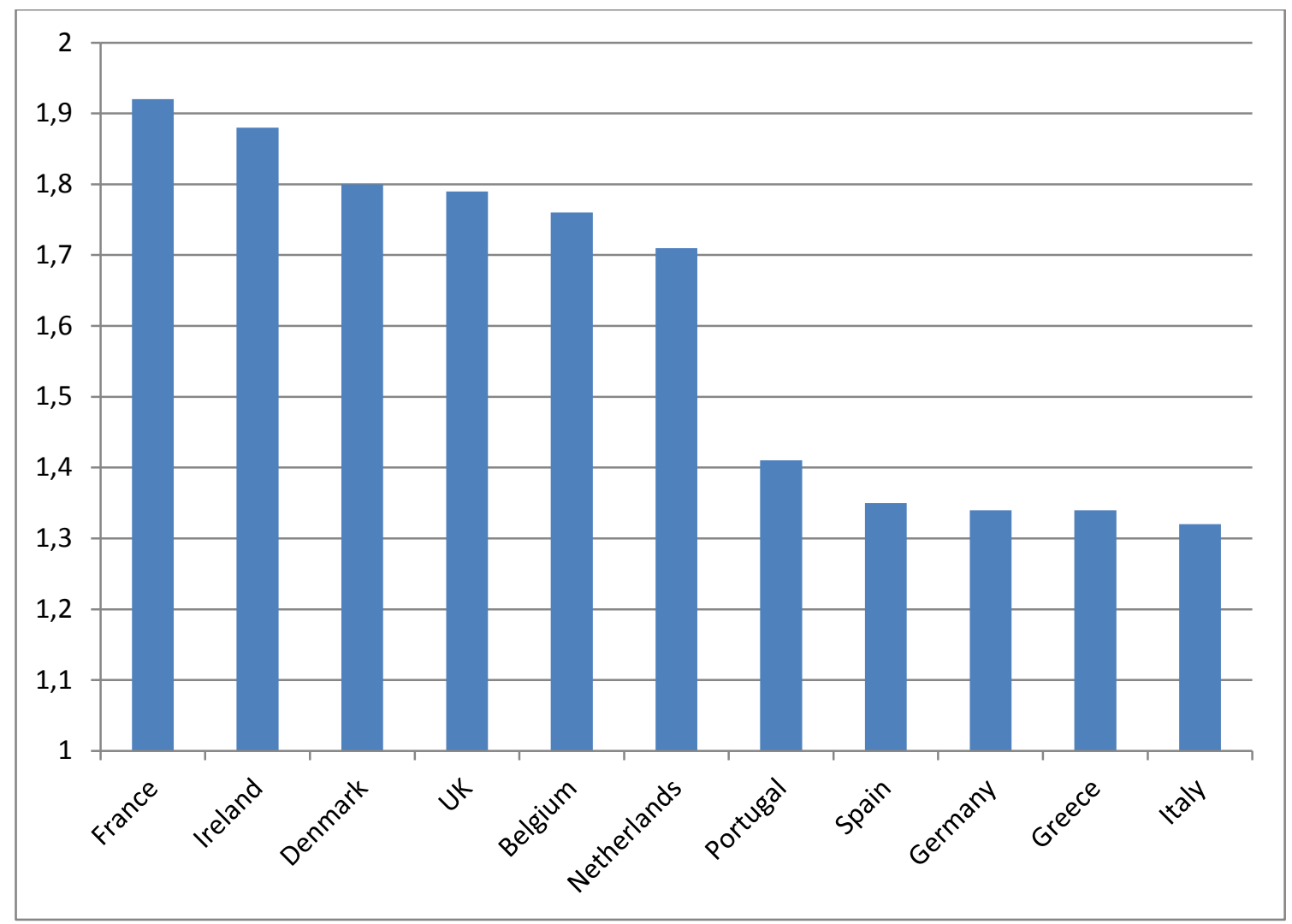

In relation to the aggregate index for family support shown in Figure 4, it should be emphasized that indicators of family friendly policies are based on a broad number of variables or parameters showing quite big variation across time and countries. This conceptual problem contributes to explain the challenge in the literature of finding a stable relationship between family policy and indicators of fertility, see also Neyer (2012).

A solution to this challenge is further complicated by the fact that consistent data series usually do not cover the long period including as well years before as years after the big fertility transition, cf. Figures 1 and 2. An exception is Björklund (2006) containing data for 11 countries between 1960 and 1985 on an aggregate of the value of tax credits, cash benefits and tax allowances to families with children as a share of the net income of an average industrial worker. In 9 out of these 11 countries the share was increasing between 1960 and 1985, i.e. in exactly the period where fertility drops dramatically ${ }^{2}$. This seems to be a dramatic illustration of the counteracting impact on fertility from increasing labor force participation among married women over this period. Kalwij (2010)

\footnotetext{
${ }^{2}$ The two countries with a decreasing share had the highest initial levels among the 11 countries.
} 
analyzes the impact on fertility in 16 European countries from family policy using data from the European Social Survey for 2004. Overall, Kalwij (2010) finds a positive but small effect from family policies on fertility. Kalwij (2010) includes three specific programs. The first, family allowance, is found to have no effect on fertility. In contrast to this, maternity and parental leave and childcare provisions have significant effects as they reduce the opportunity costs of having children and thereby facilitate having a job and children at the same time. Kalwij (2010) includes data on the average annual change from 1980 to 2003, i.e. the majority of years after the great fertility transition, for the three specific expenditure programs, cf. above. Comparability over time seems to be present for mean family allowance and mean maternity and parental leave benefits while child care subsidies seems to be nearly absent until the turn of the century in Portugal and Spain making average annual change over the full period irrelevant. For the two first indicators, the average annual changes are negative for Portugal, Spain, Italy and Greece ${ }^{3}$. This is the countries experiencing dramatic declines in fertility since 1980.

One possible aspect in the decline in fertility could obviously be an increase in the share of women who remain childless. Calculated from data in Kalwij (2010), Figure 6 shows estimates of the share of women who remain childless based on data from European Social Survey from 2004. The simple correlation with the fertility data in Figure 5 is -0.75 . The current low level of fertility accordingly could be in part explained by a high level of childlessness. However, strong conclusions should not be based on this short-run correlation. Caution on this concern is motivated in Rowland (1998) presenting data on the total proportion of childless women in Australia at ages 45-49 years for female cohorts born 1851-56 to 1952-57. A peak in childlessness is found at about 30 per cent for the birth cohorts 1901-1906. For most of the fertile life stage for those cohorts fertility however increases from just above replacement level, slightly above 2, to a level of 3.5 in the mid-1950s.

\footnotetext{
${ }^{3}$ Except a small positive change for mean maternity leave in Spain.
} 
Figure 6. Share of women who remain childless. (European Social Survey, 2004)

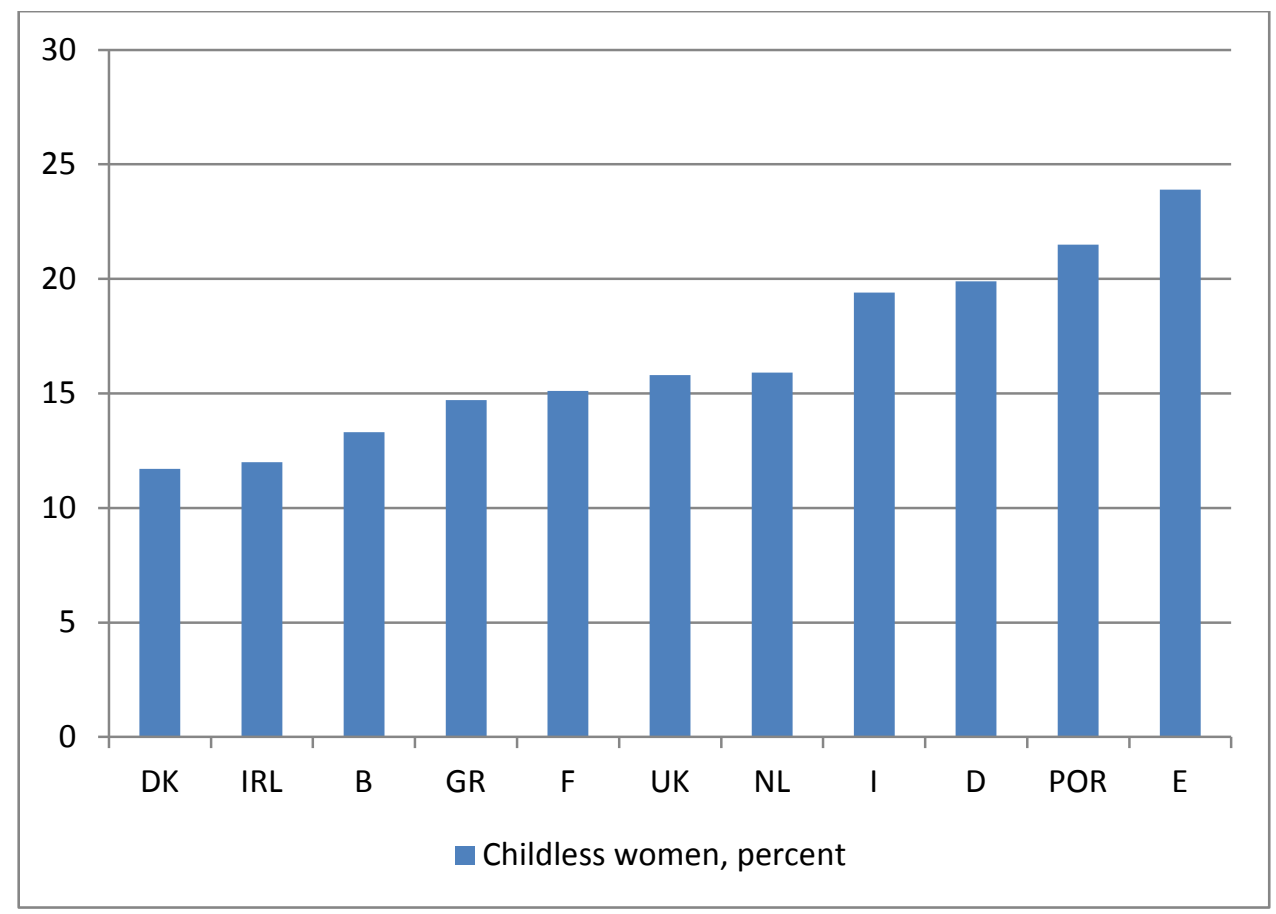

A very comprehensive survey of the area discussed here is found in Thévenon (2011). The survey emphasizes the diversity in family friendly policies across countries and their stability - or lack of stability - over time in specific countries. Thévenon (2011) concludes that differences in financial support to families targeting the direct cost of children has a positive but small effect on fertility rates. Further, availability of childcare solutions appears to contribute in explaining cross-country differences in fertility. The final conclusion in Thévenon (2011) is that the effect of policies on total fertility rates is relatively small. The eventual relations between fertility and SWB is taken up in subsequent sections.

\section{Descriptive evidence}

In this section we present descriptive evidence regarding the impact from giving birth to your first, respectively your second child. We use data from the ECHP on 11 EU countries ${ }^{4}$ and restrict the sample to focus on married and cohabiting women only, following the suggestion in Angeles (2010a). To be more specific we study a sample consisting of married or cohabiting women, 20 -

\footnotetext{
${ }^{4}$ The analysis is restricted to the 11 EU countries with the necessary data for the analyses in the ECHP.
} 
42 years old in the year of giving birth to a first or a second child ${ }^{5}$. In the first round we focus on births in 1996 being the 3 . wave of the panel and calculate for each country the average value of the variable PK001, measuring general satisfaction, for the two years, wave 1 and 2, before the year of the birth in wave 3 , and for the five years after the birth. Next, we calculate an average over all countries using number of observations in each country as weights. For births of the first child these averages are shown in Figure 7. Country average values are shown in the Appendix, Table A1.

Figure 7. Weighted average of satisfaction variable for married women having their first child in w3 (1996).

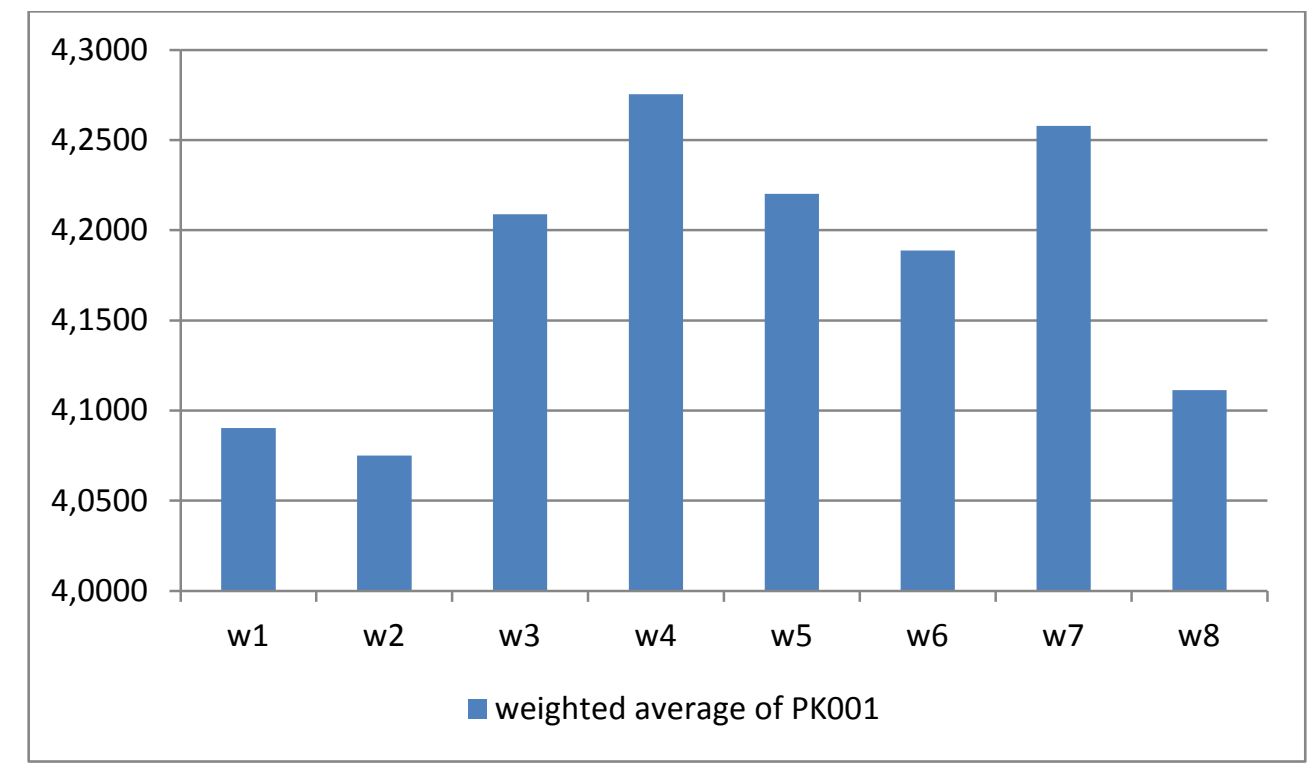

Three observations follow from Figure 7. First, while the variation in the average values is small, it seems evident that there is a jump up in the year where the first birth occurs, compared with a lower and fairly stationary level in the two preceding years. Secondly, the average level of satisfaction seems to remain at the new slightly higher level at least for the next five years. Finally, there does not seem to be any anticipation effect on SWB of having a first child in the year immediately before the birth.

\footnotetext{
${ }^{5}$ A birth is identified by HD010 "Number of members born". A first birth is identified by the difference HD001 "Household size" - HD003 "Number of adults in the household" being 0 in the period prior to HD010 taking the value 1. We according only consider single births and not births of twins or more.
} 
Figure 8. Weighted average of satisfaction variable for married women having their second child in w3 (1996).

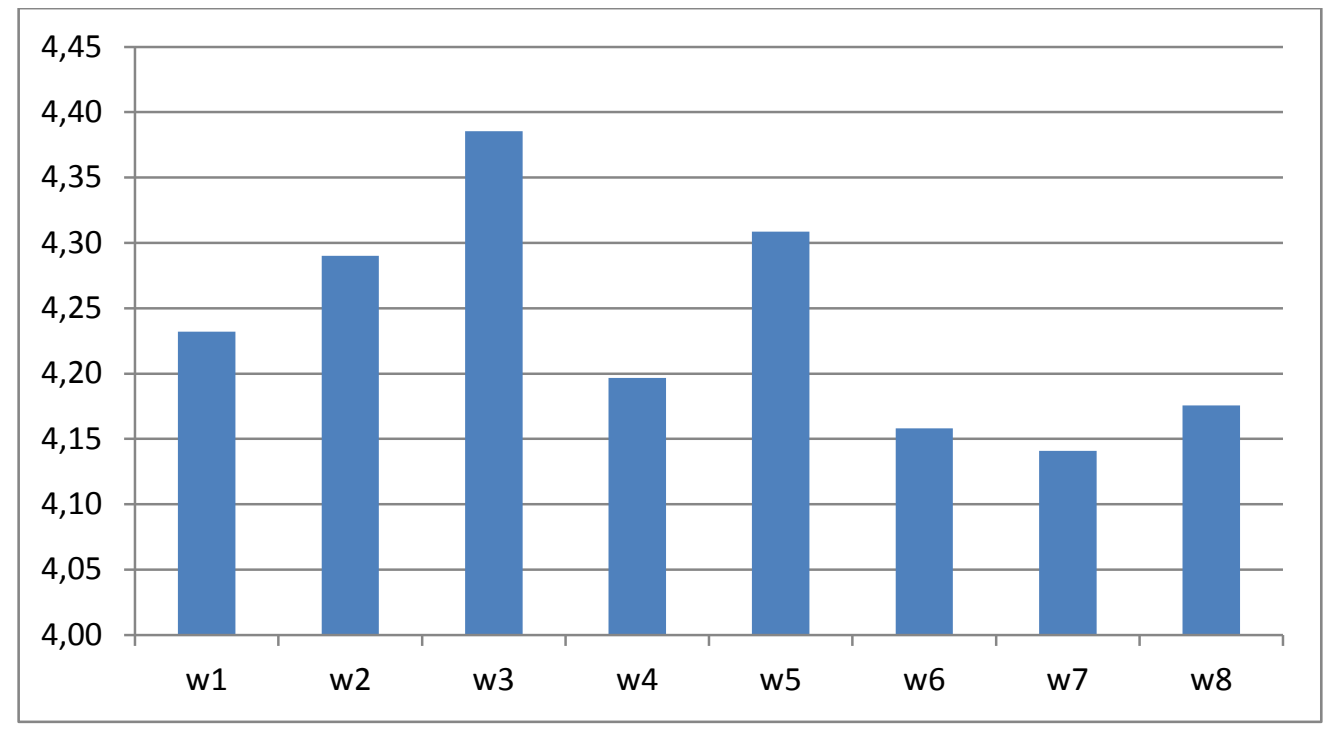

Figure 8 shows the result from making the same type of calculation for the event of having a second child $^{6}$. The number of observations is somewhat higher here as the population under "risk" is somewhat higher consisting of all married or cohabiting women in the specific age group having one child already. As in Figure 7 the differences are small, however we find a peak in the year of having the second child. The jump up from the two preceding years is much less pronounced than for the first birth and might be interpreted as anticipation being better founded in a situation where a veil of ignorance has been lifted as the women in Figure 8 has one child already. On average, satisfaction after the second birth declines to below the pre-birth level ${ }^{7}$.

In Figures 7 and 8 the idea is to use the 8 waves in the ECHP panel in a way giving the option of following satisfaction two years before giving birth and the maximum number of years after the event of birth of either first or second child ${ }^{8}$. Another approach is shown in Figure 9. We still focus on observations both before and after a first birth. To maximize the number of observations we select a moving 4 years window as observation period, of which the 8 years long panel allows us 5 windows. In each 4 years window, we calculate the average satisfaction in the year before a first

\footnotetext{
${ }^{6}$ The birth of a second child is identified similarly to a first child, only now HD001-HD003 increases from 1 in period $\mathrm{t}-1$ to 2 in period $\mathrm{t}$.

${ }^{7}$ We have also looked into the question of whether spacing between the first and the second birth is important for swb of the mothers. The spacing differs between countries in the interval between 1.8 and 2.8 years. The average swb at the time of the second birth among those who have their first birth in wave 3 is slightly higher that at the time of the first birth.

${ }^{8}$ We have extracted the same type of data as those behind Figures 7 and 8 for a third birth. The number of observations are however too small for analysis.
} 
birth, in the year having your first child and in the two years after the first birth. Throughout, the calculations are based on married or cohabiting women 20-42 years old in the year of the birth. The resulting 5 windows with average satisfaction profiles are shown in Figures A1-A5 in the appendix where country average values are weighted by number of observations. Figures A1-A5 shows a jump up from the year before to the year of the 1 . birth for all 5 windows. For four of the five windows it turns out that the peak value is in the year of birth. Finally, we have aggregated the five 4-year windows by weighting with the number of observations. The result from this "super aggregation” is shown in Figure 9. Once again, the differences are small, but based on nearly 8.000 observations it seems fairly convincing that the first birth on average increases subjective wellbeing for married or cohabiting women across Europe ${ }^{9}$.

Figure 9. Weighted average value of satisfaction based on all 1. birth observations with the option of observing satisfaction as well before as after the birth

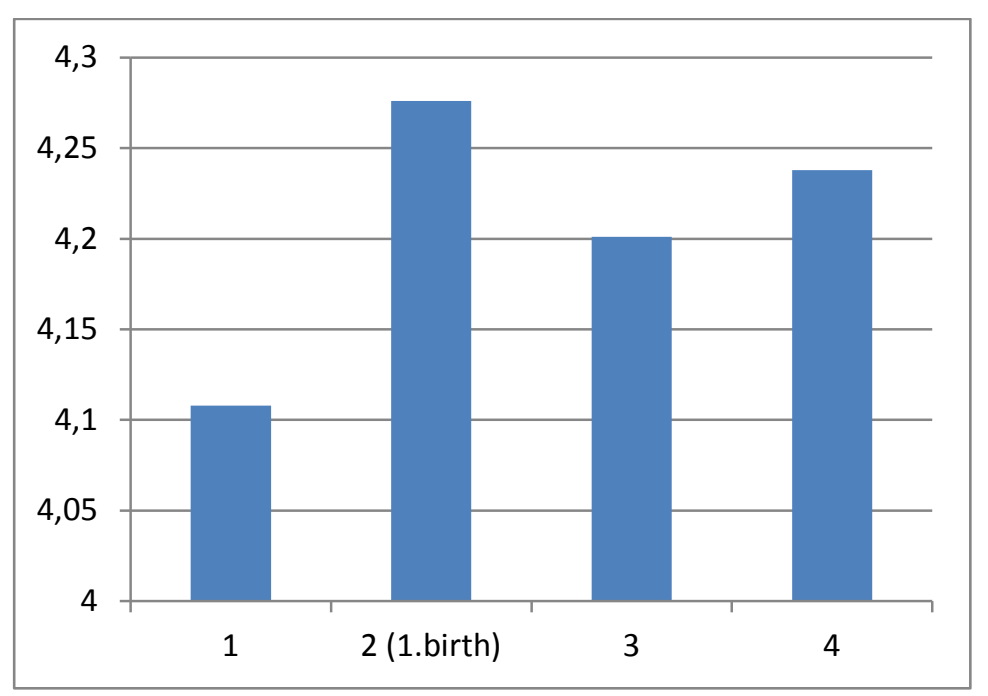

Finally, the GSOEP data offers a possibility for looking into the impact on SWB from the 1. birth over significantly longer periods. The focus in Figure 10 is an attempt to identify eventual anticipation effects up to the year of giving birth to the first child and the impact on SWB from giving birth. The anticipation effect relative to having the child in year $\mathrm{t}$ is measured in Figure 10 as $\mathrm{SWB}_{\mathrm{t}-1}-\mathrm{SWB}_{\mathrm{t}-2}$. Quite dominantly, the anticipation effect is found to be positive. The impact effect is measured in Figure 10 as $\mathrm{SWB}_{\mathrm{t}+1}-\mathrm{SWB}_{\mathrm{t}}$. It is with one exception found to be negative

\footnotetext{
${ }^{9}$ The same type of analysis has been made for the fathers. Here we find no significant effects.
} 
over the period 1991 - 2011. So, women in Germany are looking forward to their first child but the immediate reaction after the birth seems to be negative.

Figure 10. Anticipation effects and impact effect from having the first child. Calculations from GSOEP 1991-2011.

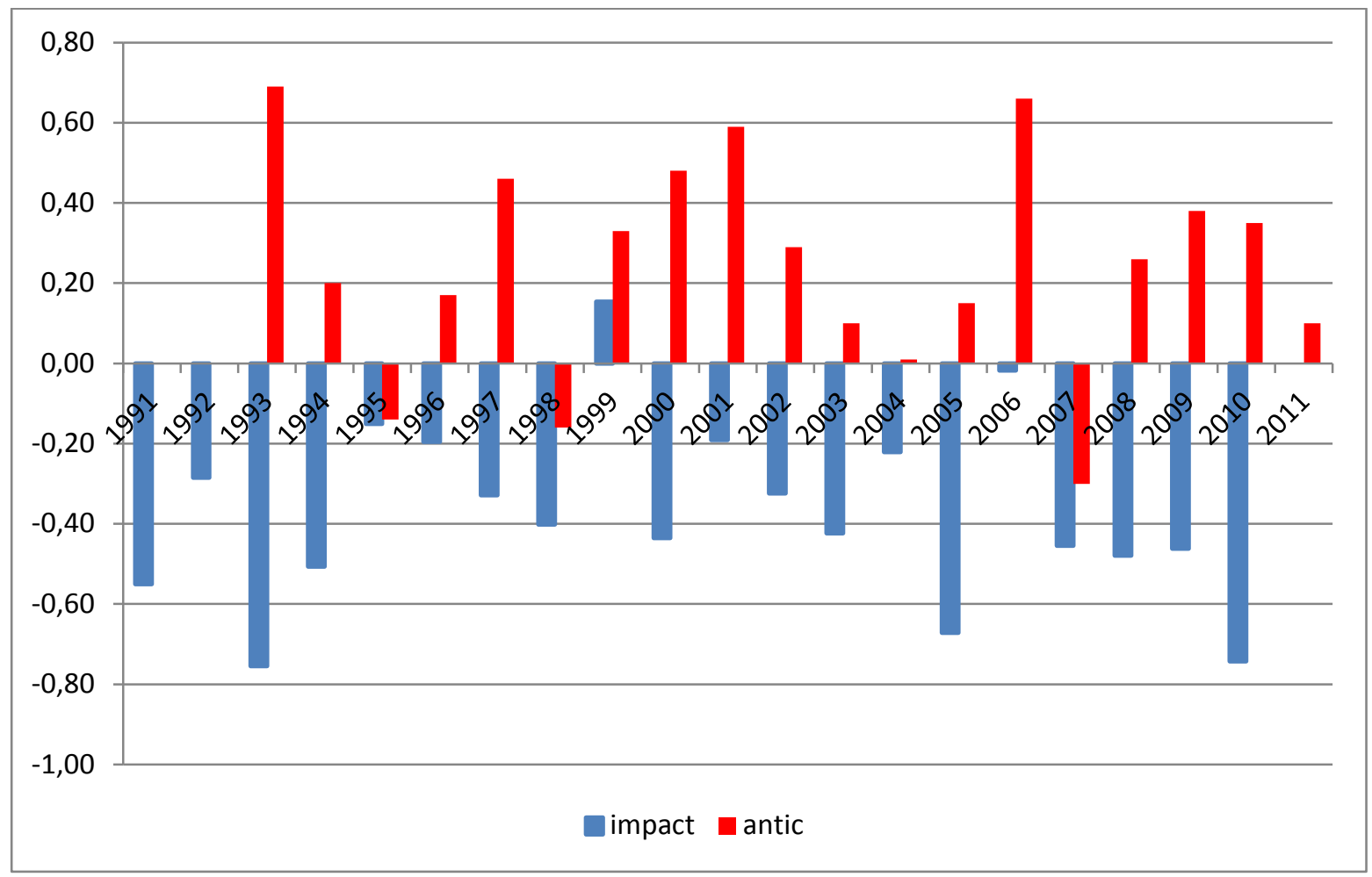

The level of subjective well-being in a longer perspective before and after a first birth is illustrated in Figures 11 and 12. In Figure 11, we look at the profile of subsequent SWB for birth taking place in 1991, 1994 and 1997. Obviously, other facts and events in life can occur in the next, up to 20 years after the birth. However, the profiles look like the initial downturn immediately after a first birth, cf. Figure 10, followed by a new fairly stable level. Considering the positive anticipation effect found in Figure 10, it seems that the broad conclusion is a peak value for SWB in the year of giving birth followed by a return to the pre-birth level, i.e. full adaptation occurs to this life event. This last point is illustrated in Figure 12 showing for the birth of the first child how SWB changes from 4 years before to up to 16 years after. It is interesting to note that this is in contrast to the dip in SWB found at the birth of a child in the BHPS, cf. Clark and Georgellis (2013). The BHPS study however does not focus on the birth of the first child among married and cohabiting women, but 
more generally birth of a child. In the next Section we focus on quantitative analyses on the impact from children on mother's SWB including a number of control variables in a cross-country setting.

Figure 11. Average swb for mothers getting their first child in 1991, 1994 and 1997.

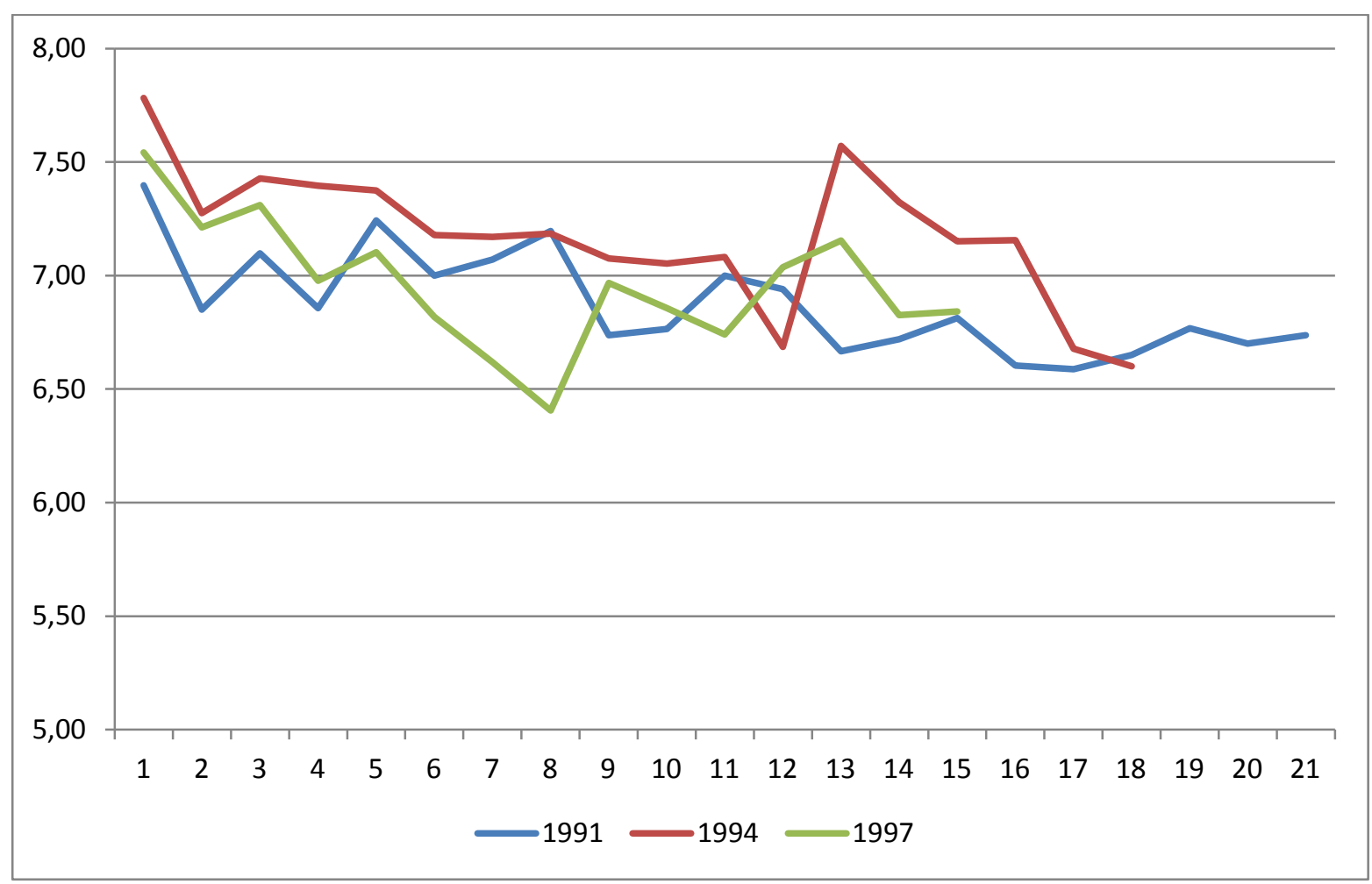


Figure 12. Average swb for mothers having their first child in 1995, 1998 and 2001, from 4 years before birth to up til 16 years after.

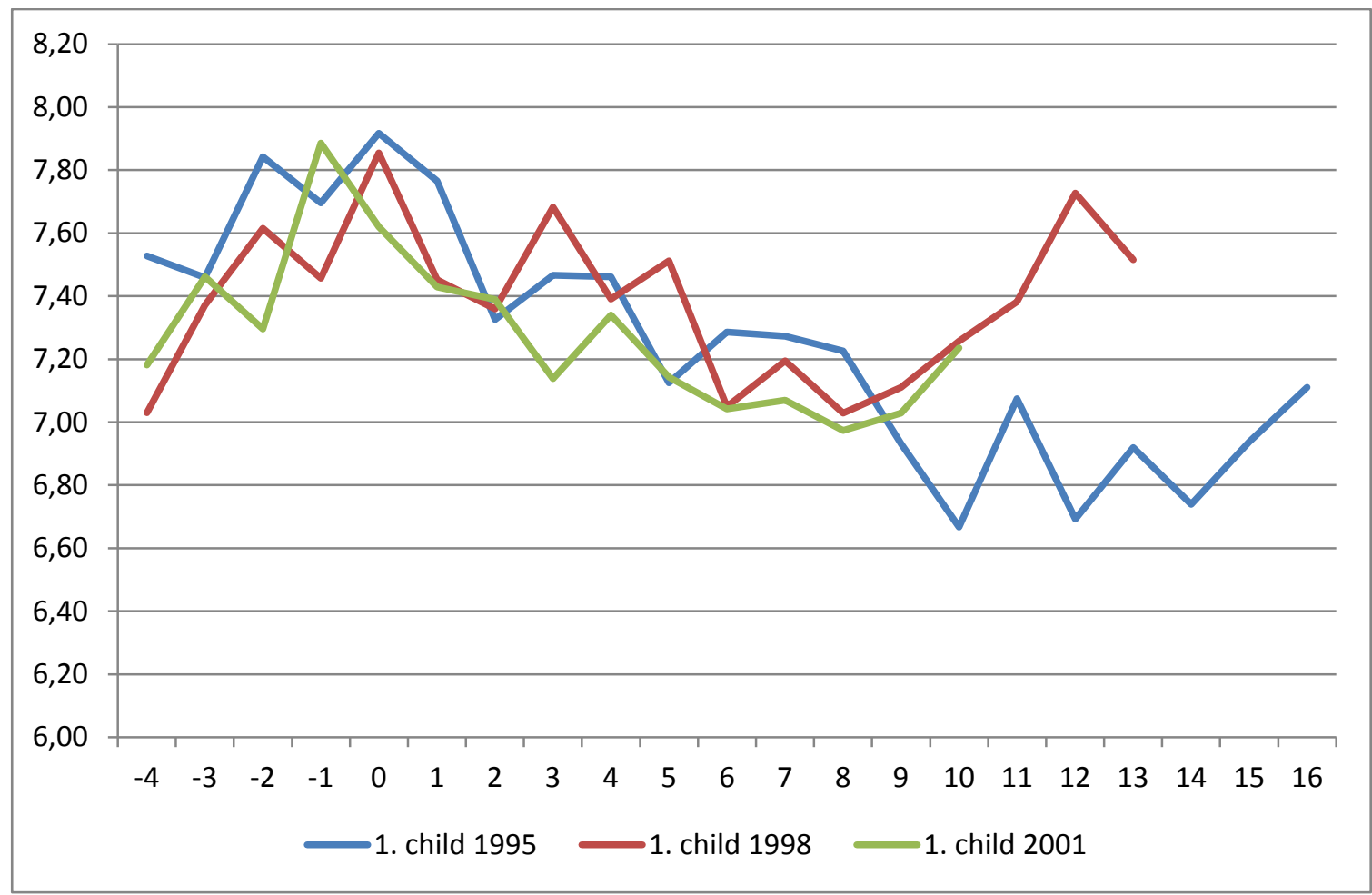

\section{Some estimation results}

The purpose in this section is to analyze if the impact found in the descriptive survey in Section 5 is supported controlling for other important covariates than giving birth in estimations of the satisfaction variable. As a beginning we use the ECHP data to examine whether having children per se has a significant impact or not on the satisfaction variable. A first round of results from panel logit estimations are presented in Table 1 . The left hand side variable is the satisfaction variable PK001 with 6 possible outcomes converted to a binary variable set at 1 for PK001 $=\{4,5,6\}$ and set at 0 for PK001 $=\{1,2,3\}$. The sample being used in the estimation is all married or cohabiting women 20-42 years old in all waves of the ECHP. The explanatory variable in focus is the number of children which is also entered squared to capture possible non-linearities in the eventual impact. Further, a number of covariates are included. The first one, eqinc, is the equivalence scale adjusted household income. Next, mainacti is a binary variable set at 1 if the main self reported activity is being in the labor force (either working or unemployed) and set at 0 otherwise. The variable badhealth is a self-reported health evaluation converted from a 5 point scale to be a binary variable. 
Education is entered at two levels with basic school education as the left out category. Finally crime is a binary indicator for the neighbourhood in which the respondent lives ${ }^{10}$.

Regarding the results we find a significant impact from the number of children for 5 out of 11 countries. The impact is significant and positive for Spain, France, Greece, Ireland, and the UK. If this can be interpreted in terms of welfare state types, an impact is found in some of the Southern European welfare states with low fertility, except in Portugal, and in the liberal type of welfare states consisting here of Ireland and UK. France does not fit into this pattern. In the North European continental and social democratic welfare states there is - with Belgium as an exception - no impact from the number of children. For France, Ireland and the UK, we further find indications of a non-linearity in the number of children. The covariates mostly have the expected signs. The variable for main activity of the women (mainacti) has mixed effects, probably reflecting differences in family policies relative to having children.

In Table 2 we report the results in panel logit estimations from using the event of giving birth to the first child as explanatory variable along with covariates. We include married and cohabiting women 20 - 42 years old as in the descriptive analysis above. We find a significant positive impact from the first birth in all the countries, except Belgium, Denmark and UK. Equivalence scale adjusted income (eqinc) has a significant positive impact on SWB in 7 of the 11 countries. As in Table 1, the evidence is inconclusive regarding the impact from labor force attachment or not. Health problems have the expected negative impact. In 7 of the countries education beyond mandatory school has a positive impact on SWB. We include three age interval dummies for the married or cohabiting women in the selected age group, with 35 - 42 years old as excluded group. We find a certain concentration of negative impacts on SWB from being in the younger age groups in Greece, Portugal and especially in Italy which might be related to the very low fertility in these countries. ${ }^{11}$. Finally, the GSOEP data gives an opportunity to test the relationship between SWB and the number of children in the family along with covariates for a longer period than the ECHP years. Table 5 shows the results from a pooled probit analysis of the relation between the SWB variable being 6 or higher and a number of explanatory variables for married or cohabiting women 25 - 55 years old in each of the years 1991 - 2011. Year dummies are not shown in the table.

\footnotetext{
${ }^{10}$ See Table A3 of the appendix for a formal definition of the variables.

${ }^{11}$ The estimations have also been made for the group of single mothers. We find no cases with a significant impact on SWB from having the first child for single mothers.
} 
Table 5. Impact on mothers well-being from having children in the family. GSOEP data, 1991 2011.

\begin{tabular}{|l|c|c|}
\hline & Coefficient & Z value \\
\hline Number of children 0-7 years old & 0,0352 & 1,49 \\
\hline Number of children 8 - 15 years old & 0,0013 & 0,07 \\
\hline Age of mother & 0,0071 & 3,73 \\
\hline Education & 0,0086 & 0,20 \\
\hline Health & 0,2240 & 31,24 \\
\hline Labor force & $-0,1134$ & $-3,59$ \\
\hline Adjusted income & $1,2018 \mathrm{E}-8$ & 12,80 \\
\hline Constant & $-1,7414$ & $-9,76$ \\
\hline Year dummies, 1991 - 2011 & & 9519 \\
\hline Number of observations & & 0,1247 \\
\hline Adj. ${ }^{2}$ & & \\
\hline
\end{tabular}

There is no significant impact on SWB from children in the family. Age, health and equivalence scale adjusted household income are all significant and positive. Being in the labor force has a significantly negative coefficient which may reflect problems combining family with work life in Germany.

\section{Conclusions}

Broad consensus is lacking regarding the relationship between satisfaction/happiness and having children, respectively giving birth to a child. The relationship seems to be important in policy terms and relevant in a more broad approach recognizing the very big structural changes occurring over the last 50 years. In descriptive analyses using the ECHP data we find convincing evidence that there is on average in Europe a positive impact on satisfaction for married and cohabitating women from having especially the first child and to a lesser extent from having the second child. The impact is however small in absolute magnitude. In subsequent multivariate analyses using ECHP data we find significant positive effects both from having children in the family, defined here to include only married or cohabitating women, and from giving birth to a first and a second child. This is not the case for all countries in the ECHP but most systematically so for the Southern 
European countries and for UK and Ireland representing the liberal type of welfare state. For the Continental and the Social democratic welfare state, we find no impact on satisfaction from having children or from birth of a child. It is well known that the eventual relationship between family policy and fertility is complex. The same is true regarding the relationship between fertility and subjective well-being from having children in the family or from having your first child. There is a tendency in the results found here of an inverse relationship between happiness and fertility.

\section{Literature}

Aassve, A., S. Massuco and L. Mencarini. 2005. Childbearing and Well-being: A Comparative Analysis of the European Community. Journal of European Social Policy, Vol. 15, No. 4: 283-299.

Angeles, L. 2010a. Children and Life Satisfaction. Journal of Happiness Studies, 11, 4: 523-538.

Angeles, L. 2010b. Adaptation and anticipation effects to life events in the United Kingdom. Mimeo. Department of Economics. University of Glasgow.

Becker, G.S. 1981. A Treatise on the Family. Cambridge MA. Harvard University Press.

Björklund, A. 2006. Does family policy affect fertility? Lessons from Sweden. Journal of Population Economics, 19: 324.

Blanchflower, D.G. 2009. International Evidence on Well-Being. Ch. 7 in A.B. Krueger (ed.) Measuring the Subjective Well-Being of Nations. National Accounts of Time Use and Well-Being. NBER. Chicago University Press.

Cáceres_Delpiano, J. And M. Simonsen. 2010. The Toll of Fertility on Mothers 'Wellbeing. Department of Economics, University Carlos III Madrid, Working Paper 10-06.

Clark, A.E. and A.J. Oswald. 2002. A simple statistical method for measuring how life events affect happiness. International Journal of Epidemiology, 31: 1139-1144.

Clark, A., E. Diener, Y. Georgellis and R.E. Lucas. 2008. Lags and Leads in life satisfaction: a test of the baseline hypothesis. The Economic Journal, 118, June: F222-F243.

Clark, A.E. and Y. Georgellis. 2013. Back to baseline in Britain: Adaptation in the BHPS. Economica, 80 (319): 496512.

Engelhardt, H., and A. Prskawetz. 2005. A Pooled Time-Series Analysis on the Relation Between Fertility and Female Employment. European Demographic Research Papers 1. Vienna Institute of Demography.

Engster, D. and H.O. Stensöta. 2011. Do Family Policy Regimrs Matter for Children's Well-Being? Social Politics, Vol. 18, no. 1: 82-124.

Esping-Andersen, G. 1990. The Three Worlds of Welfare Capitalism. Princeton University Press.

Ferrera, M. 1996. The “Southern Model” of welfare in social Europe. Journal of European Social Policy, 6(1): 17-37.

Goldstein, J.R., M. Kreyenfeld, A. Jasilioniene and D.K. Örsal. 2013. Fertility reactions to the “Great Recession” in Europe: Recent evidence from order-specific data. Demographic Research, vol. 29, article 4: 85-104.

Hansen, T. 2012. Parenthood and Happiness: a Review of Folk Theories Versus Empirical Evidence. Social Indicators Research, 108: 29-64. 
Hansen, T., B. Slagsvold and T. Moum. 2009. Childlessness and Psychological Well-being in Midlife and Old Age: An Examination of Parental Status Effects Across a Range of Outcomes. Social Indicators Research, 94(2) : 343-362.

Hillerås, P.K., H. Aguero-Torres and B. Winblad. 2001. Factors influencing well-being in the elderly. Current Opinion in Psychiatry, 14(4): 361-365.

Kalwij, A. 2010. The impact of family policy expenditure on fertility in Western Europe. Demography, 47, 2: 503-519.

Kohler, H.-P., J.R. Behrman and A. Skytthe. 2005. Partner + Children = Happiness? The Effects of Partnerships and Fertility on Well-Being. Population and Development Review, Vol. 31, 3: 407-445.

Korpi, W. 2000. Faces of Inequality: Gender, Class, and Patterns of Inequalities in Different Types of Welfare States. Social Politics, 7(2): 127-91.

Margolis, R. And M. Myrskylä. 2011. A Global Perspective on Happiness and Fertility. Population and Development Review 37(1): 29-56.

Myrskylä, M. and R. Margolis. 2012. Happiness: Before and After the Kids. Max Planck Institute for DemographicResearch. Working Paper 2012-013.

Neyer, G. 2012. Welfare States, Family Policies, and Fertility in Europe. Stockholm University Linnaeus Center on Social Policy and Family Dynamics in Europe, SPaDE. Working Paper 2012:10.

Pedersen, P.J. and T. Dall Schmidt. 2011. Happiness in Europe. Cross-country differences in the determinants of satisfaction with main activity. The Journal of Socio-Economics, Vol. 40: 480-489

Plagnol, A.C. and J. Scott. 2011. What Matters for Well-Being: Individual Perceptions of Quality of Life Before and After Important Life Events. Applied Research in Quality of Life, Vol. 6, No.2: 115-138.

Rowland, D.T. 1998. The Prevalence of Childlessness in Cohorts of Older Women. Australasian Journal on Ageing,17(1): 18-23.

Powdthavee, N. 2010. And You Think Having Children Will Make You Happy! A Case of Focusing Illusion. Mimeo.

Suh, E., E. Diener and F. Fujita. 1996. Events and subjective well-being: only recent events matter. Journal of Personal Social Psychology, 70: 1091-1102.

Thévenon, O. 2011. Family Policies in OECD Countries: A Comparative Analysis. Population and Development Review 37(1): 57-87.

Veenhoven, R. 2002. Commentary: The units of utility. International Journal of Epidemiology, 31: 1144-1146 
Figure A1. Weighted average of satisfaction variable for married women having their first child in 1995.

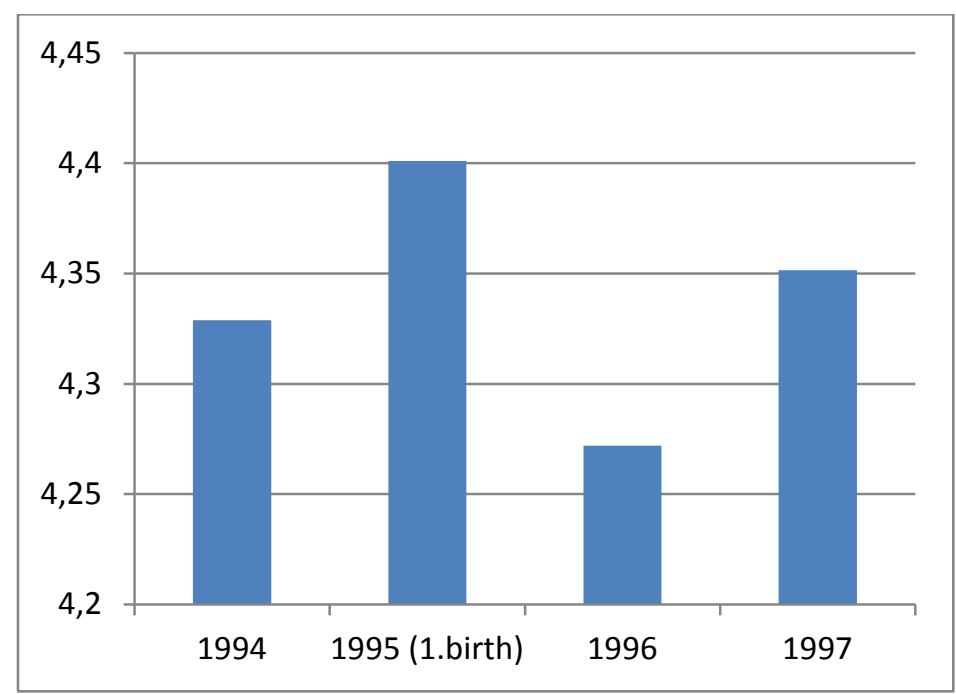

Figure A2. Weighted average of satisfaction variable for married women having their first child in 1996.

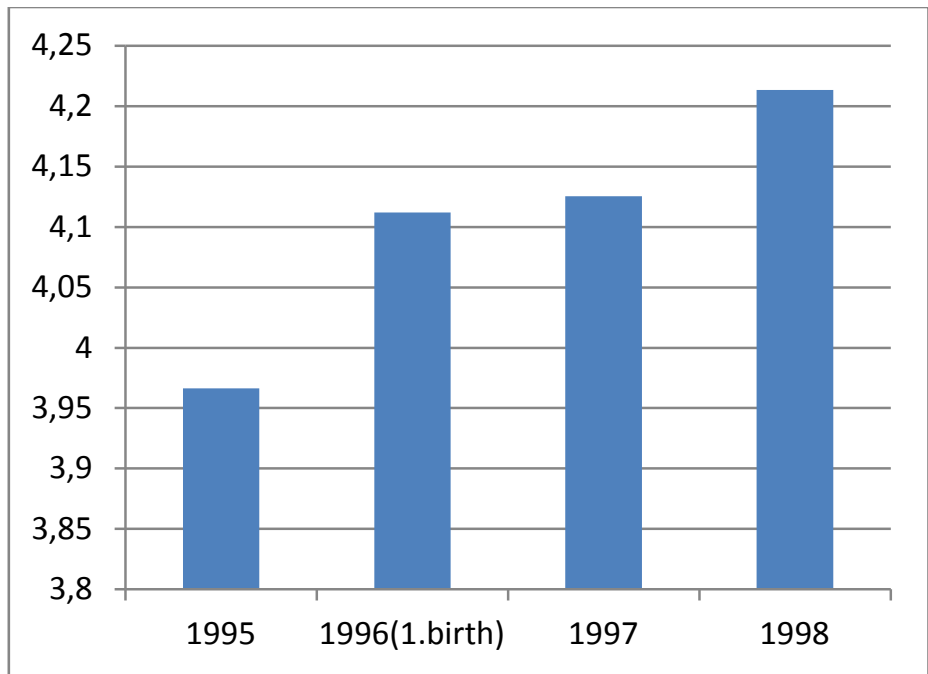


Figure A3. Weighted average of satisfaction variable for married women having their first child in 1997.

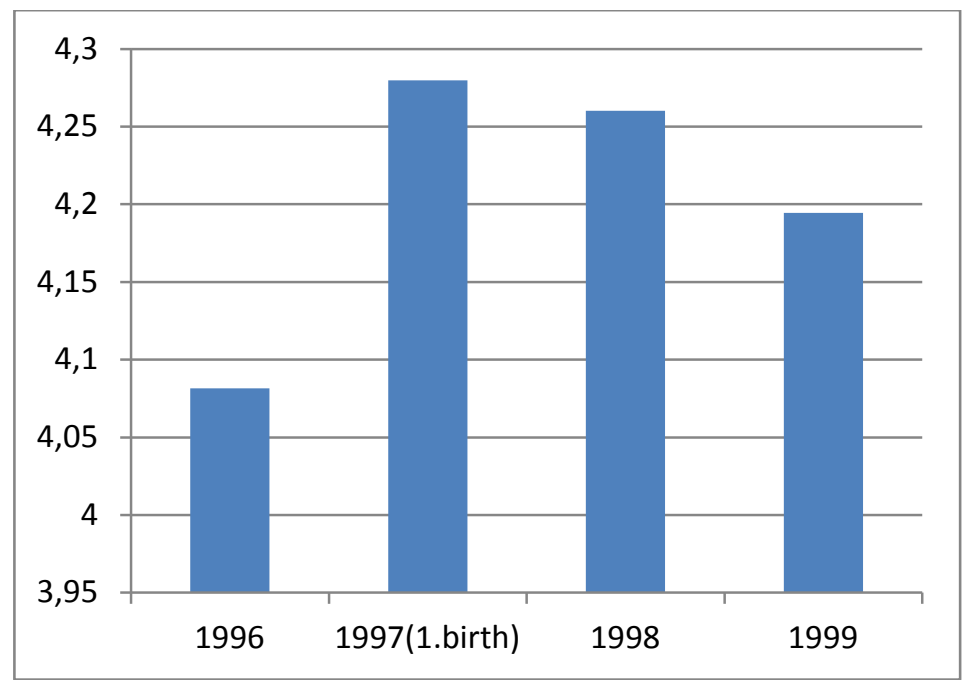

Figure A4. Weighted average of satisfaction variable for married women having their first child in 1998.

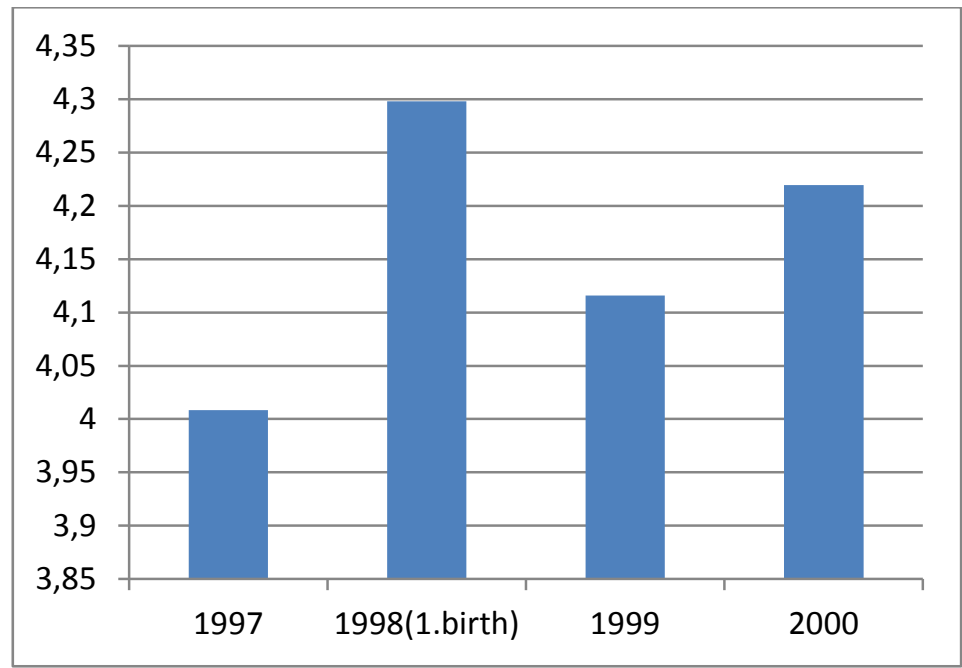


Figure A5. Weighted average of satisfaction variable for married women having their first child in 1999.

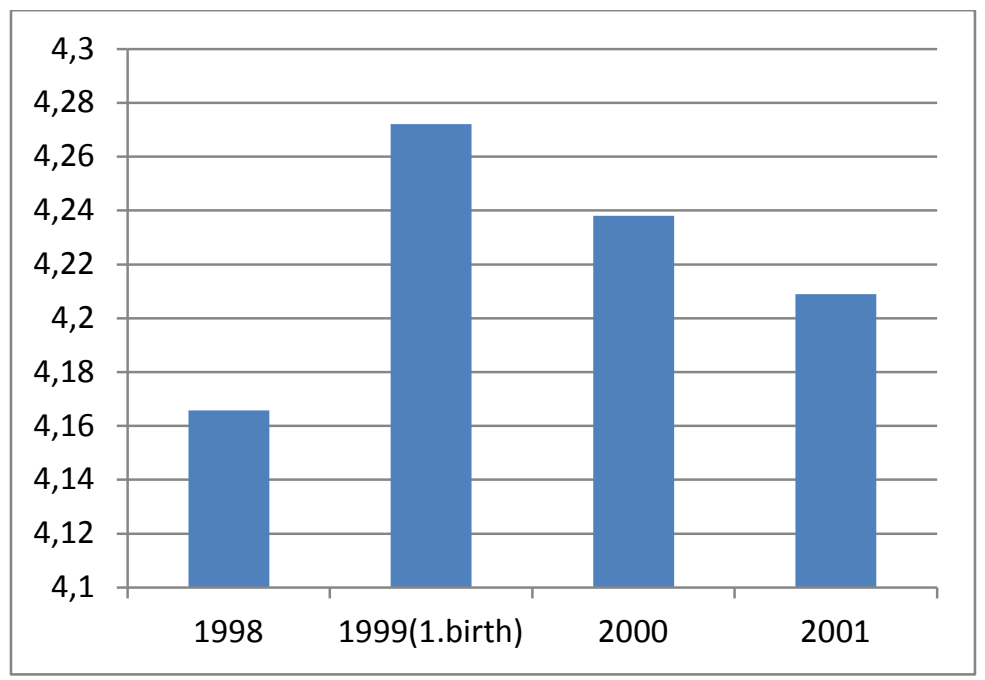


Table 1. Coefficients in panel logit estimations on satisfaction, married or cohabiting mothers aged 20 to 42 of the ECHP

\begin{tabular}{|c|c|c|c|c|c|c|c|c|c|c|c|}
\hline & Belgium & Denmark & Spain & France & Germany & Greece & Ireland & Italy & Netherlands & Portugal & UK \\
\hline \multirow[t]{2}{*}{ children14 } & $-0.234 *$ & $\begin{array}{l}-0.0784 \\
\end{array}$ & $0.290 * * *$ & $0.396 * * *$ & 0.0108 & $0.171^{* *}$ & $0.292^{* * *}$ & 0.134 & 0.140 & 0.0567 & $0.299 * * *$ \\
\hline & $(0.120)$ & $(0.153)$ & $(0.0679)$ & $(0.0800)$ & $(0.108)$ & $(0.0860)$ & $(0.107)$ & $(0.0816)$ & $(0.105)$ & $(0.0844)$ & $(0.106)$ \\
\hline \multirow[t]{2}{*}{ children14sq } & $0.0626^{*}$ & 0.0547 & $-0.0588^{* * *}$ & $-0.0538 * * *$ & -0.00954 & -0.0340 & $-0.0587 * * *$ & -0.00592 & -0.0348 & -0.0340 & $-0.0557 *$ \\
\hline & $(0.0336)$ & $(0.0486)$ & $(0.0215)$ & $(0.0204)$ & $(0.0272)$ & $(0.0305)$ & $(0.0218)$ & $(0.0283)$ & $(0.0298)$ & $(0.0213)$ & $(0.0314)$ \\
\hline \multirow[t]{2}{*}{ eqiinc } & $0.596 * * *$ & 0.897 & $0.472 * * *$ & $4.129 * * *$ & $16.77 * * *$ & $0.555 * * *$ & $50.84 * * *$ & $47.93 * * *$ & 6.033* & $0.802 * * *$ & 0.239 \\
\hline & $(0.201)$ & (1.372) & $(0.0467)$ & $(0.969)$ & (4.259) & $(0.0354)$ & (15.66) & (3.794) & (3.520) & $(0.0961)$ & (6.553) \\
\hline \multirow[t]{2}{*}{ mainacti } & 0.0515 & 0.0277 & $-0.167 * * *$ & $-0.571^{* * *}$ & 0.188 & 0.0969 & $0.229 * *$ & $0.549 * * *$ & -0.143 & $0.740 * * *$ & $0.323^{* * *}$ \\
\hline & $(0.137)$ & $(0.152)$ & $(0.0558)$ & $(0.0896)$ & $(0.116)$ & $(0.0649)$ & $(0.111)$ & $(0.0666)$ & $(0.0993)$ & $(0.0895)$ & $(0.108)$ \\
\hline \multirow[t]{2}{*}{ badhealth } & $-0.869 * * *$ & $-0.812^{* * *}$ & $-0.260 * * *$ & $-0.594 * * *$ & $-0.764 * * *$ & $-0.453 * * *$ & $-0.748 * * *$ & $-0.411 * * *$ & $-1.068^{* * *}$ & -0.0419 & $-0.657 * * *$ \\
\hline & $(0.114)$ & $(0.151)$ & $(0.0651)$ & $(0.0719)$ & $(0.119)$ & $(0.122)$ & $(0.133)$ & $(0.0593)$ & $(0.0962)$ & $(0.0756)$ & $(0.0891)$ \\
\hline \multirow[t]{2}{*}{ secondeduc } & 0.138 & $0.444 * * *$ & 0.0561 & $0.240^{* *}$ & $0.326 * *$ & $0.422 * * *$ & $0.197^{*}$ & $0.456 * * *$ & $0.208^{*}$ & $0.968 * * *$ & 0.169 \\
\hline & $(0.137)$ & $(0.152)$ & $(0.0722)$ & $(0.0945)$ & $(0.127)$ & $(0.0756)$ & $(0.120)$ & $(0.0771)$ & $(0.124)$ & $(0.141)$ & $(0.115)$ \\
\hline \multirow[t]{2}{*}{ thirdeduc } & $0.745^{* * *}$ & $0.844^{* * *}$ & $0.346^{* * *}$ & $0.507 * * *$ & $0.364 * *$ & $0.696 * * *$ & $0.596^{* * *}$ & $0.746^{* * *}$ & -0.0741 & $1.558 * * *$ & 0.0651 \\
\hline & $(0.153)$ & $(0.175)$ & $(0.0818)$ & $(0.116)$ & $(0.177)$ & $(0.0965)$ & $(0.188)$ & $(0.143)$ & $(0.150)$ & $(0.236)$ & $(0.109)$ \\
\hline \multirow[t]{2}{*}{ crime } & $-0.228^{*}$ & $-0.454^{* * *}$ & $-0.276^{* * *}$ & $-0.312^{* * *}$ & $-0.342^{* *}$ & 0.188 & $-0.313^{* *}$ & -0.0861 & -0.167 & -0.133 & $-0.207^{* *}$ \\
\hline & $(0.118)$ & $(0.148)$ & $(0.0626)$ & $(0.0794)$ & $(0.139)$ & $(0.116)$ & $(0.130)$ & $(0.0754)$ & $(0.104)$ & $(0.116)$ & $(0.0953)$ \\
\hline \multirow[t]{2}{*}{ aged20to24 } & $-0.469 * *$ & -0.200 & -0.0422 & $-0.436 * * *$ & 0.0506 & $-0.282^{* *}$ & 0.296 & $-0.490 * * *$ & $0.399^{*}$ & $-0.354^{* * *}$ & -0.133 \\
\hline & $(0.213)$ & $(0.203)$ & $(0.115)$ & $(0.143)$ & $(0.216)$ & $(0.112)$ & $(0.253)$ & $(0.146)$ & $(0.212)$ & $(0.132)$ & $(0.151)$ \\
\hline \multirow[t]{2}{*}{ aged25to29 } & -0.206 & -0.239 & 0.0237 & -0.154 & -0.0809 & $-0.356 * * *$ & -0.0830 & -0.133 & $0.248^{*}$ & $-0.237^{* *}$ & -0.126 \\
\hline & $(0.143)$ & $(0.159)$ & $(0.0737)$ & $(0.104)$ & $(0.140)$ & $(0.0846)$ & $(0.145)$ & $(0.0875)$ & $(0.132)$ & $(0.112)$ & $(0.117)$ \\
\hline \multirow[t]{2}{*}{ aged30to34 } & -0.00330 & $-0.266^{*}$ & 0.0589 & 0.0233 & -0.0475 & $-0.232 * * *$ & $-0.207 *$ & -0.0692 & 0.0720 & 0.0420 & -0.0813 \\
\hline & $(0.113)$ & $(0.142)$ & $(0.0612)$ & $(0.0899)$ & $(0.123)$ & $(0.0739)$ & $(0.111)$ & $(0.0676)$ & $(0.104)$ & $(0.0936)$ & $(0.103)$ \\
\hline \multirow[t]{2}{*}{ Constant } & $1.220 * * *$ & $2.339 * * *$ & $0.238 * *$ & $1.799 * * *$ & $1.056^{* * *}$ & $-0.993 * * *$ & $1.113^{* * *}$ & $-0.863^{* * *}$ & $2.821^{* * *}$ & $-0.504 * * *$ & $1.757 * * *$ \\
\hline & $(0.227)$ & $(0.309)$ & $(0.0988)$ & $(0.166)$ & $(0.212)$ & $(0.103)$ & $(0.203)$ & $(0.116)$ & $(0.216)$ & $(0.154)$ & $(0.181)$ \\
\hline \multirow[t]{2}{*}{ lnsig2u } & $0.917 * * *$ & $0.440^{* * *}$ & $0.231^{* * *}$ & $0.947^{* * *}$ & $0.517 * * *$ & $0.308^{* * *}$ & $0.409^{* * *}$ & $1.141^{* * *}$ & $0.843^{* * *}$ & $1.174^{* * *}$ & $0.817^{* * *}$ \\
\hline & $(0.102)$ & $(0.157)$ & $(0.0731)$ & $(0.0788)$ & $(0.143)$ & $(0.0800)$ & $(0.128)$ & $(0.0577)$ & $(0.0998)$ & $(0.0720)$ & $(0.103)$ \\
\hline Observations & 5991 & 5479 & 12687 & 11581 & 4221 & 9993 & 5446 & 14569 & 11078 & 9787 & 8204 \\
\hline Number of PID & 1463 & 1463 & 3260 & 2839 & 1687 & 2344 & 1461 & 3491 & 2779 & 2370 & 3363 \\
\hline
\end{tabular}

Note: The estimation results are obtained from a panel dataset across eight waves of the ECHP. Dummies for waves have been included in the estimation procedure, but are suppressed in the reported results above. Some dummies have during the estimation procedure been dropped due to collinearity. 
Table 2. Coefficients in panel logit estimations on satisfaction, married or cohabiting mothers aged 20 to 42 of the ECHP from giving birth to the 1 . child

\begin{tabular}{|c|c|c|c|c|c|c|c|c|c|c|c|}
\hline & Belgium & Denmark & Spain & France & Germany & Greece & Ireland & Italy & Netherlands & Portugal & UK \\
\hline \multirow[t]{2}{*}{ Firstbirth } & -0.395 & 0.202 & $0.312 *$ & $0.425 *$ & 0.833* & $0.499 * *$ & $0.806^{*}$ & $0.282^{*}$ & $1.408 * * *$ & $0.362 *$ & $\begin{array}{l}-0.0526 \\
\end{array}$ \\
\hline & $(0.285)$ & (0.373) & (0.163) & $(0.236)$ & $\begin{array}{l}(0.448) \\
\end{array}$ & $(0.216)$ & $(0.437)$ & $(0.144)$ & $(0.456)$ & $(0.211)$ & $(0.248)$ \\
\hline \multirow[t]{2}{*}{ Eqiinc } & $0.643 * *$ & 2.632 & $0.430 * * *$ & $4.090 * * *$ & $16.88 * * *$ & $0.574 * * *$ & 23.48 & $46.64 * * *$ & 4.651 & $0.708 * * *$ & -6.448 \\
\hline & $(0.290)$ & $(1.900)$ & $(0.0584)$ & $(1.270)$ & $(4.956)$ & $(0.0504)$ & $(22.60)$ & (4.618) & $(4.297)$ & $(0.119)$ & $(8.747)$ \\
\hline \multirow[t]{2}{*}{ Mainacti } & $0.469 * *$ & -0.335 & -0.0852 & $-0.538 * * *$ & $0.379 * *$ & -0.117 & 0.336 & $0.622 * * *$ & 0.177 & $0.853 * * *$ & 0.0870 \\
\hline & $(0.219)$ & $(0.226)$ & $(0.0794)$ & $(0.148)$ & $(0.157)$ & $(0.0983)$ & $(0.219)$ & $(0.0880)$ & $(0.163)$ & $(0.124)$ & $(0.171)$ \\
\hline \multirow[t]{2}{*}{ badhealth } & $-0.967 * * *$ & $-0.843 * * *$ & $-0.172 *$ & $-0.537 * * *$ & $-0.837 * * *$ & $-0.344 * *$ & $-0.582 * *$ & $-0.407 * * *$ & $-1.275^{* * *}$ & -0.0137 & $-0.690 * * *$ \\
\hline & $(0.172)$ & $(0.222)$ & $(0.0940)$ & $(0.111)$ & $(0.155)$ & $(0.166)$ & $(0.254)$ & $(0.0806)$ & $(0.134)$ & $(0.105)$ & $(0.118)$ \\
\hline \multirow[t]{2}{*}{ secondeduc } & -0.0213 & $0.443^{*}$ & -0.0285 & $0.300 * *$ & $0.348^{* *}$ & $0.420^{* * *}$ & 0.341 & $0.383^{* * *}$ & 0.168 & $0.990^{* * *}$ & $0.314^{*}$ \\
\hline & $(0.206)$ & $(0.226)$ & $(0.0999)$ & $(0.146)$ & $(0.168)$ & $(0.121)$ & $(0.222)$ & $(0.0995)$ & $(0.173)$ & $(0.176)$ & $(0.163)$ \\
\hline \multirow[t]{2}{*}{ thirdeduc } & $0.677 * * *$ & $1.005^{* * *}$ & $0.266 * *$ & $0.406^{* *}$ & 0.0107 & $0.753^{* * *}$ & $0.883^{* * *}$ & $0.642^{* * *}$ & -0.152 & $1.588^{* * *}$ & 0.121 \\
\hline & $(0.239)$ & $(0.270)$ & $(0.109)$ & $(0.169)$ & $(0.227)$ & $(0.150)$ & $(0.322)$ & $(0.181)$ & $(0.206)$ & $(0.302)$ & $(0.147)$ \\
\hline \multirow[t]{2}{*}{ Crime } & $-0.388^{* *}$ & $-0.393^{*}$ & $-0.359 * * *$ & $-0.274^{* *}$ & -0.178 & 0.228 & -0.357 & -0.131 & -0.216 & -0.103 & -0.0428 \\
\hline & $(0.177)$ & $(0.210)$ & $(0.0906)$ & $(0.124)$ & $(0.173)$ & $(0.171)$ & $(0.242)$ & $(0.101)$ & $(0.144)$ & $(0.152)$ & $(0.132)$ \\
\hline \multirow[t]{2}{*}{ aged20to24 } & -0.233 & -0.0788 & -0.190 & $-0.762^{* * *}$ & -0.0706 & $-0.266^{*}$ & 0.464 & $-0.514^{* * *}$ & 0.325 & $-0.401^{* *}$ & -0.131 \\
\hline & $(0.264)$ & $(0.260)$ & $(0.139)$ & $(0.177)$ & $(0.230)$ & $(0.156)$ & $(0.345)$ & $(0.168)$ & $(0.230)$ & $(0.163)$ & $(0.178)$ \\
\hline \multirow[t]{2}{*}{ aged25to29 } & $-0.419^{* *}$ & -0.225 & $\begin{array}{l}-0.0941 \\
\end{array}$ & -0.249 & -0.149 & $-0.253^{*}$ & -0.0400 & $-0.221^{* *}$ & 0.00275 & $-0.376^{* *}$ & -0.122 \\
\hline & $(0.205)$ & $(0.235)$ & $(0.0990)$ & $(0.157)$ & $(0.175)$ & $(0.134)$ & $(0.252)$ & $(0.111)$ & $(0.164)$ & $(0.153)$ & $(0.152)$ \\
\hline \multirow[t]{2}{*}{ aged30to34 } & -0.264 & -0.380 & -0.0225 & -0.151 & -0.122 & -0.121 & -0.255 & $-0.190 *$ & -0.103 & -0.208 & -0.0683 \\
\hline & $(0.193)$ & $(0.259)$ & $(0.0959)$ & $(0.161)$ & $(0.171)$ & $(0.128)$ & $(0.234)$ & $(0.0978)$ & $(0.166)$ & $(0.142)$ & $(0.150)$ \\
\hline \multirow[t]{2}{*}{ Constant } & $1.155^{* * *}$ & $2.406^{* * *}$ & $0.475^{* * *}$ & $2.015^{* * *}$ & $0.916^{* * *}$ & $-0.946^{* * *}$ & $1.257 * * *$ & $-0.706^{* * *}$ & $2.843^{* * *}$ & $-0.588^{* * *}$ & $2.051 * * *$ \\
\hline & $(0.301)$ & $(0.403)$ & $(0.112)$ & $(0.225)$ & $(0.232)$ & $(0.129)$ & $(0.256)$ & $(0.128)$ & $(0.279)$ & $(0.184)$ & $(0.224)$ \\
\hline \multirow[t]{2}{*}{ lnsig2u } & $1.038^{* * * *}$ & $0.744 * * *$ & $0.303 * * *$ & $1.070 * * *$ & $0.376 *$ & $0.487 * * *$ & 0.311 & $1.100 * * *$ & $0.536 * * *$ & $1.194 * * *$ & $0.889 * * *$ \\
\hline & $(0.155)$ & $(0.215)$ & $(0.102)$ & $(0.121)$ & $(0.205)$ & $(0.118)$ & $(0.255)$ & $(0.0794)$ & $(0.170)$ & $(0.0989)$ & $(0.134)$ \\
\hline Observations & 2615 & 2537 & 6408 & 4764 & 2462 & 4468 & 1548 & 7993 & 4887 & 5419 & 4580 \\
\hline Number of PID & 2776 & 851 & 1985 & 1509 & 1031 & 1313 & 544 & 2265 & 1491 & 1543 & 1980 \\
\hline
\end{tabular}

Note: The estimation results are obtained from a panel dataset across eight waves of the ECHP. Dummies for waves have been included in the estimation procedure, but are suppressed in the reported results above. Some dummies have during the estimation procedure been dropped due to collinearity. 


\section{Appendix}

Table A1. Average value of satisfaction variable. Sample of married women having their first child in w3.

\begin{tabular}{|c|c|c|c|c|c|c|c|c|c|c|c|}
\hline & Belgium & Denmark & Spain & France & Germany & Greece & Ireland & Italy & Netherlands & Portugal & UK \\
\hline & 4 & 2 & 11 & 6 & 10 & 8 & 9 & 3 & 12 & 57 & \\
\hline w1 & 4,5625 & 4,9474 & 2,6667 & 4,1892 & 3,1200 & 4,3333 & 3,4103 & 4,9091 & 4,0000 & 4,4545 & 4,0903 \\
\hline$w 2$ & 4,1176 & 4,3684 & 1,6667 & 4,2703 & 3,7200 & 4,6667 & 3,5250 & 4,5909 & 3,7500 & 4,6667 & 4,0750 \\
\hline w3 & 4,0000 & 4,4444 & 3,3333 & 4,5676 & 3,4000 & 5,0000 & 3,7250 & 5,0909 & 4,0000 & 4,5417 & 4,2089 \\
\hline w4 & 4,3158 & 4,5263 & 3,6667 & 4,4324 & 3,9600 & 4,6667 & 3,8000 & 4,6365 & 4,0833 & 4,6800 & 4,2754 \\
\hline w5 & 4,4706 & 5,2105 & 2,3333 & 4,6486 & 3,0800 & 4,3333 & 3,9300 & 4,3182 & 4,0833 & 4,4348 & 4,2201 \\
\hline w6 & 4,3889 & 4,8421 & 2,3333 & 4,7838 & 3,2000 & 4,3333 & 3,7000 & 4,6364 & 4,0000 & 4,3182 & 4,1887 \\
\hline w7 & 4,2105 & 4,9474 & 3,3333 & 4,8108 & 3,8000 & 4,3333 & 3,6250 & 4,5909 & 3,9167 & 4,3684 & 4,2577 \\
\hline w8 & 4,2222 & 4,8947 & 4,3333 & 4,4865 & 3,0400 & 5,3333 & 3,5385 & 4,8636 & 3,6667 & 4,2273 & 4,1114 \\
\hline obs & 143 & 151 & 24 & 296 & 200 & 24 & 318 & 176 & 96 & 198 & 1626 \\
\hline
\end{tabular}


Table A 2. Average value of satisfaction variable. Sample of married women having their second child in w3.

\begin{tabular}{|l|r|r|r|r|r|r|r|r|r|r|r|}
\hline & \multicolumn{1}{l}{ lelgium } & \multicolumn{1}{l}{ Denmark } & \multicolumn{1}{l}{ lpain } & \multicolumn{1}{l}{ lrance } & \multicolumn{1}{l}{ Greece } & Ireland & Italy & Netherlands & Portugal & UK & Weighted \\
\hline & 4 & 2 & 11 & 6 & 10 & 8 & 9 & 3 & 12 & 57 & Average \\
\hline w1 & 4,3333 & 4,8000 & 4,0000 & 4,6279 & 3,5676 & 4,7778 & 3,5455 & 4,5641 & 3,9355 & 4,6333 & 4,2322 \\
\hline w2 & 4,4667 & 4,9500 & 5,0000 & 4,6512 & 3,4865 & 5,2000 & 3,4242 & 4,7179 & 3,8387 & 4,7500 & 4,2901 \\
\hline w3 & 4,5333 & 4,7778 & 5,0000 & 5,0233 & 3,5000 & 5,4000 & 3,5455 & 4,9231 & 3,8065 & 4,6364 & 4,3854 \\
\hline w4 & 4,8000 & 4,5263 & 4,0000 & 4,7907 & 3,3889 & 4,4444 & 3,6364 & 4,5385 & 3,5000 & 4,7619 & 4,1966 \\
\hline w5 & 4,6875 & 5,0000 & 3,6667 & 4,8837 & 3,5135 & 5,0000 & 3,6061 & 4,7949 & 3,7097 & 4,5000 & 4,3084 \\
\hline w6 & 4,5625 & 4,6500 & 3,6667 & 4,6512 & 3,2973 & 4,8000 & 3,5758 & 4,6923 & 3,7097 & 4,2857 & 4,1579 \\
\hline w7 & 4,5000 & 4,6500 & 3,8333 & 4,4884 & 3,5946 & 4,7778 & 3,1212 & 4,6667 & 3,7333 & 4,6000 & 4,1407 \\
\hline w8 & 4,6250 & 5,0000 & 3,6667 & 4,3953 & 3,5135 & 4,8889 & 3,4848 & 4,5897 & 3,6452 & 4,6296 & 4,1755 \\
\hline & & & & & & & & & & & \\
\hline obs & 124 & 157 & 48 & 344 & 288 & 75 & 264 & 312 & 246 & 187 & 2045 \\
\hline
\end{tabular}


Table A 3. Variable definition for ECHP variables.

\begin{tabular}{|c|c|}
\hline satspliteq & satspliteq $=0$ if pk001 $=\{1,2,3\}$ and satspliteq $=1$ if $p k 001=\{4,5,6\}$ and satspliteq $=$. if $p k 001=\{-8,-9\}$ \\
\hline eqiinc & $\begin{array}{l}\text { hi100/(hd004*1000000) where hi100 and hd } 004 \text { have been corrected such that hi100 }=\{-8,-9\} \text { or } \\
\text { hd004 }=\{-8,-9\} \text { has been set to respectively hi100 }=\text {. and hd004=. }\end{array}$ \\
\hline children14 & hd001-hd003 \\
\hline mainacti & $\begin{array}{l}\text { mainacti }=1 \text { if pe } 001=\{1,2,3,4,7\} \text { and mainacti }=0 \text { if pe } 001=\{5,6,7,9,10,11,12\} \text { and mainacti }=\text {. } \\
\text { Otherwise }\end{array}$ \\
\hline secondeduc & secondeduc $=1$ if pt $022=2$ and secondeduc $=0$ if pt $022=\{1,3\}$ and secondeduc $=$. Otherwise \\
\hline thirdeduc & thirdeduc $=1$ if pt $022=1$ and thirdeduc $=0$ if pt $022=\{2,3\}$ and thirdeduc $=$. otherwise \\
\hline badhealth & badhealth $=1$ if ph001 $=\{3,4,5\}$ and badhealth $=0$ if ph001 $=\{1,2\}$ and badhealth $=$. otherwise \\
\hline crime & crime $=1$ if ha $022=1$ and crime $=0$ if ha $022=2$ and ha $021=$. otherwise \\
\hline aged20to24 & pd003 $>=20$ and $p d 003<=24$ \\
\hline aged25to29 & pd003 $>=25$ and $p d 003<=29$ \\
\hline aged30to34 & pd003 $>=30$ and $p d 003<=34$ \\
\hline
\end{tabular}

